Author version: Clim. Dyn., vol.40; 2013; 2049-2071

\title{
TropFlux wind stresses over the tropical oceans: evaluation and comparison with other products
}

\author{
B. Praveen Kumar ${ }^{1}$, J. Vialard ${ }^{2}$, M. Lengaigne ${ }^{1,2}$, V.S.N. Murty ${ }^{3}$, M.J. McPhaden ${ }^{4}$,
} M.F. Cronin ${ }^{4}$, F. Pinsard ${ }^{2}$ and K. Gopala Reddy ${ }^{5}$

1. National Institute of Oceanography, Council of Scientific and Industrial Research, Dona Paula, Goa, India

2. Laboratoire d'Océanographie Expérimentation et Approches Numériques, CNRS, UPMC, IRD, Paris, France

3. National Institute of Oceanography, Regional Centre, Vishakhapatnam, India

4. NOAA/Pacific Marine Environmental Laboratory, Seattle, WA, USA

5. Centre for Bay of Bengal Studies, Department of Meteorology and Oceanography, Andhra University, Vishakhapatnam, India

Submitted to Climate Dynamics, $1^{\text {st }}$ April 2012

Revised version, 14 $4^{\text {th }}$ June 2012

Accepted on $10^{\text {th }}$ July 2012

\section{Corresponding author address:}

B. Praveen Kumar

Physical Oceanography Division

National Instittute of Oceanography

Dona Paula, Goa - 403004

India

E-mail: bpraveen@nio.org 


\begin{abstract}
In this paper, we present TropFlux wind stresses and evaluate them against observations along with other widely used daily air-sea momentum flux products (NCEP, NCEP2, ERA-I and QuikSCAT). TropFlux wind stresses are computed from the COARE v3.0 algorithm, using bias and amplitude corrected ERA-I input data and an additional climatological gustiness correction. The wind stress products are evaluated against dependent data from the TAO/TRITON, PIRATA and RAMA arrays and independent data from the OceanSITES mooring networks. Wind stress products are more consistent amongst each other than surface heat fluxes, suggesting that $10 \mathrm{~m}$-winds are better constrained than near-surface thermodynamical parameters (2m-humidity and temperature) and surface downward radiative fluxes. QuikSCAT overestimates wind stresses away from the equator, while NCEP and NCEP2 underestimate wind stresses, especially in the equatorial Pacific. QuikSCAT wind stress quality is strongly affected by rain under the Inter Tropical Convergence Zones. ERA-I and TropFlux display the best agreement with in-situ data, with correlations $>0.93$ and rms-differences $<0.012 \mathrm{Nm}^{-2}$. TropFlux wind stresses exhibit a small, but consistent improvement (at all timescales and most locations) over ERA-I, with an overall 17\% reduction in root mean square error. ERA-I and TropFlux agree best with long-term mean zonal wind stress observations at equatorial latitudes. All products tend to underestimate the zonal wind stress seasonal cycle by $\sim 20 \%$ in the western and central Equatorial Pacific. TropFlux and ERA-I equatorial zonal wind stresses have clearly the best phase agreement with mooring data at intraseasonal and interannual timescales (correlation of $\sim 0.9$ versus $\sim 0.8$ at best for any other product), with TropFlux correcting the $\sim 13 \%$ underestimation of ERA-I variance at both timescales. For example, TropFlux was the best at reproducing westerly wind bursts that played a key role in the 1997-98 El Niño onset. Hence, we recommend the use of TropFlux for studies of equatorial ocean dynamics.
\end{abstract}

Key words: TropFlux, tropics, air-sea momentum fluxes, wind stress products validation. 


\section{Introduction}

The tropics are home to many climatically relevant phenomena. The two most spectacular examples of such globally relevant modes of climate variability are the El Niño Southern Oscillation (ENSO) and Madden-Julian Oscillation (MJO). ENSO is the strongest mode of interannual climate variability on the planet (e.g., McPhaden et al. 2006). Although it largely arises from positive air-sea feedbacks in the tropical Pacific, it has consequences that are felt around the world. The MJO is the dominant mode of intraseasonal variability, with worldwide teleconnections (e.g. Zhang 2005) including impacts on weather over the North Atlantic (Cassou 2008). There is also well-known ocean-atmosphere interannual variability in the Indian Ocean (the Indian Ocean Dipole or IOD, e.g., Saji et al. 1999; Webster et al. 1999) and in the tropical Atlantic (the Atlantic Meridional Mode, e.g., Xie and Carton 2004).

For most of the aforementioned climate phenomena, air-sea interactions play an essential role. For instance, ENSO and IOD events grow as a result of the so-called Bjerknes feedback (e.g., Bjerknes 1966; Wang and Picaut 2004; Annamalai et al. 2003). The Bjerknes feedback involves the following loop: surface momentum flux anomalies induce changes in ocean circulation that lead to the growth of Sea Surface Temperature (SST) anomalies, which in turn reinforce the original momentum flux anomalies. Surface momentum fluxes (i.e. wind stresses, generally expressed in units of $\mathrm{Nm}^{-2}$ ) are hence an essential measure of the air-sea coupling in the Bjerknes feedback. While ocean-atmosphere coupling is associated to a larger extent with surface heat fluxes rather than to surface wind stresses for MJO events (e.g. Duvel and Vialard 2007, Jayakumar et al. 2011, Drushka et al. 2011, Vialard et al. 2012), equatorial wind stress perturbations associated with the MJO drive strong basin-wide dynamical response, both in the Indian Ocean (e.g., Han et al. 2011; Vialard et al. 2009; Nagura and McPhaden 2012) and the Pacific Ocean (e.g., Zhang and McPhaden 2006; Lengaigne et al. 2002). Westerly wind bursts in the western equatorial Pacific induce westward currents in the central Pacific that play a key role in the westward migration of the warm pool associated with the onset of El- Niño events (Lengaigne et al. 2004). At decadal timescales, there is also evidence of clear, Indo-Pacific wide sea level variations forced by wind stress variations (e.g., Lee and McPhaden 2008; Han et al. 2010; Nidheesh et al. 2012).

Wind stress is not only important in air-sea interactions and forced oceanic variability, as mentioned above, but also plays an important role in the tropical mean state. The pressure gradient associated with climatological east-west tilt of the thermocline in the tropical Pacific and Atlantic oceans is to first order in balance with zonal wind stress (e.g., McCreary 1981). The strong Wyrtki 
jets that develop in spring and fall in the equatorial Indian Ocean result from the semi-annual relaxation of the weak westerlies that otherwise prevail (e.g. Schott and McCreary 2001; Nagura and McPhaden. 2010a). Away from the equator, wind stress curl also plays a prominent role in setting equatorial current systems like the South Equatorial Current or North Equatorial Counter-Current in the Atlantic and Pacific oceans (Rodrigues et al. 2007; Kessler et al. 2003).

Accurate knowledge of air-sea momentum fluxes is thus important to study the tropical mean state and variability from intraseasonal to decadal time-scales. Momentum fluxes are usually calculated from wind speed using the empirical formulae $\tau=\rho C_{d} w^{2}$ where $\tau$ is the wind stress magnitude, $\rho$ is surface air density, $C_{d}$ the drag coefficient, and $w$ the wind speed relative to the ocean surface (often assumed to be stationary). The drag coefficient is in principle a non-linear function of the wind speed, atmospheric stability and sea state. There is a wide choice of different methods available in literature for drag coefficient calculation (Smith 1988; Large and Pond 1981; Hellerman and Rosenstein 1983; Fairall et al. 1996, 2003). Assessing the relative merits of different drag coefficient estimation methods is not the aim of this study, and has been discussed elsewhere (Bruke et al. 2003; Kochanski et al. 2006). In this paper, we have selected the COARE v3.0 algorithm because it takes atmospheric stability into account, has been developed purposely for tropical regions, and provides an estimated accuracy of 5\% (for wind speed below $10 \mathrm{~ms}^{-1}$ ) or $10 \%$ (for wind speed from 10 to $20 \mathrm{~ms}^{-1}$ ) (Fairall et al. 2003).

While there are uncertainties in drag formulae, another source of uncertainty in surface momentum flux estimates is wind speed itself. Historically, ship-based observations provide the major source of wind data over the global oceans (e.g., Bunkar. 1976; Hellerman and Rosenstein 1983; da Silva et al. 1994; Josey and Taylor 2002). One major drawback of observation based momentum flux datasets is the poor spatial and temporal coverage of in situ measurements. In-situ observation based momentum fluxes are largely limited to frequent shipping lines in the northern hemisphere (Risien and Chelton 2008) and do not span more than one month for each cruise. In-situ observation based momentum fluxes thus generally do not exceed one-month temporal resolution. The increase in ship size and related higher anemometer heights above the ocean surface has also led to a bias towards increased wind speeds (Tokinaga and Xie 2011).

Of late, two interesting alternatives provide higher resolution wind speed datasets over the tropical oceans: satellite scatterometry and re-analyses. Satellite scatterometers are designed to measure surface wind speed and direction by electromagnetic radar backscatter from the rough ocean surface at different angles. One of the most successful and widely used scatterometer missions is 
QuikSCAT, starting in July 1999 and ending in October 2009, whose sun-synchronous orbit allowed it to sample $90 \%$ of the global ocean daily (Schlax et al. 2001). One major drawback of these efforts using satellite data products is their limited life span since most of the satellite missions last about 10 years or less. While the focus of this paper is on timely wind stresses products, we include QuikSCAT in our wind stress evaluations because it is a widely used product that was available until recently.

Re-analyses also provide an interesting alternative for estimating wind variations at high temporal resolution. Re-analyses are generated at operational weather centers using an up-to-date version of numerical weather forecasting model and data assimilation system to retrospectively reprocess past atmospheric observations over a long period. The advantage of re-analyses is that they take advantage of any relevant information to estimate wind speed (e.g., pressure, through the geostrophic relation) and use numerical models to spatially and temporally interpolate sparse data. Recent timely re-analyses include the National Centre for Environmental Prediction (NCEP reanalysis, 1948-present, Kalnay et al. 1996), the Department of Energy (DOE) or NCEP2 reanalysis (1979-present, Kanamitsu et al. 2002), and the new European Centre for Medium Range Weather Forecast interim re-analysis (ERA-I, 1979-present, Dee et al. 2011). Note also the recent effort by the OAFlux project to provide a synthesis from the various existing re-analyses and surface observations (Yu and Weller 2007). While this project provides good quality surface flux and wind data, it does not, however, yet provide surface momentum flux estimates.

Several past studies have used in-situ data to evaluate wind stress products or have compared existing products. Rienecker et al. (1996), Pegion et al. (2000) and Meissner et al. (2001) compare several satellite, in-situ and re-analysis based wind products. Bentamy et al. (1996) and Chelton and Freilich (2005) evaluate scatterometer wind stress products against mooring data. Josey and Taylor (2002) evaluate an in-situ data based wind stress climatology against climatologies derived from other in-situ datasets, re-analyses and operational wind products. Hackert et al (2001) compare winds products during the 1997-98 El Niño event through the use of an ocean general circulation model. But to our knowledge, there is no published extensive intercomparison and evaluation of recent, timely wind stress estimates from re-analyses (NCEP, NCEP2, ERA-I) against available in situ observations.

In a companion paper (Praveen Kumar et al. 2012), we introduced a new, timely air-sea heat flux product with daily resolution for the tropical region $\left(30^{\circ} \mathrm{N}-30^{\circ} \mathrm{S}\right)$ - TropFlux - and evaluated it, along with other products (NCEP, NCEP2, ERA-I, OAFlux), against available observations from the 
global tropical moored buoy array (McPhaden et al. 1998; Bourlès et al. 2008; McPhaden et al. 2010) and OceanSITES (http://www.OceanSITES.org) data. In the present paper, we build on the methodology presented in Praveen Kumar et al. (2012) to estimate TropFlux wind-stresses, and compare them with other products (NCEP, NCEP2, ERA-I and QuikSCAT wind stresses) and estimates from moored buoys. The rest of the paper is organized as follows. Section 2 describes the various datasets used in this study. In section 3, we describe the TropFlux wind stress computation methodology, and evaluate TropFlux against ERA-I, from which it is derived. A detailed evaluation and validation of TropFlux, NCEP, NCEP2, ERA-I and QuikSCAT wind stress products are provided in section 4, including a discussion of their differences at various timescales (long termbias, interannual, seasonal and intraseasonal variability), with a focus on equatorial dynamics. We summarize and discuss the main results in section 5.

\section{Datasets}

In this section we describe the various wind stress products evaluated in this paper, the (dependent) global tropical moored buoy array evaluation data, and the independent data from OceanSITES project. Praveen Kumar et al. (2012) provide a detailed description of these datasets, and we will hence present them in a more concise way below.

\section{a. Gridded data products}

We used three re-analyses (NCEP, NCEP2 and ERA-I) and one satellite based gridded wind stress product (QuikSCAT) in this study. All four daily products were re-gridded to a common $1^{\circ} \mathrm{x} 1^{\circ}$ grid.

NCEP re-analysis extends from 1948 to present, with an original 1.9 $9^{\circ}$ resolution (Kalnay et al. 1996). NCEP2 re-analysis is an alternative version of NCEP reanalysis, which addresses some of the known problems of NCEP re-analysis (Kanamitsu et al. 2002). The main modifications likely to affect wind over the oceans in NCEP2 are a new shortwave radiation and cloud scheme. NCEP2 is available from 1979 to present. We use daily average wind stresses from NCEP and NCEP2, obtained as the mean of four 6 hour-averages obtained from the first 6 hours of the 00, 06, 12, and 18UTC forecasts. The ERA-I re-analysis (Dee et al. 2011), available from 1979 to present, uses an advanced 4-D Var assimilation approach, and provides data at a higher $0.75^{\circ}$ spatial resolution. ERA-I 10m winds, $2 \mathrm{~m}$ air temperature and humidity are obtained as the mean of 4 analyzed fields at 00, 06, 12 and 18 UTC. Wind-stress from ERA-I is computed as the average of the two 12-hours forecasts starting at 00 and 12UTC. The boundary layer scheme used in the ERA-I re-analysis has a 
formulation in essence very similar to the COARE v3.0 algorithm (A. Beljaars, personal communication, 2012).

CERSAT (Centre ERS d'Archivage et de Traitement) provides gridded fields of wind parameters retrieved from the NASA (National Aeronautics and Space Administration) Scatterometer on board QuikSCAT at $0.5^{\circ}$ x $0.5^{\circ}$ resolution over the global oceans $\left(80^{\circ} \mathrm{S}-80^{\circ} \mathrm{N}\right)$ from July 1999 to November 2009 which was the end of the satellite mission (Bentamy et al. 2002). Daily average synoptic fields are obtained from discrete observations from a statistical interpolation with an objective method. QuikSCAT uses Smith (1988) drag coefficient scheme for stress computation, but only takes wind speed variation into account (surface air temperature and humidity variations are neglected). Several studies (e.g., Milliff et al. 2004; Gille et al. 2005; Bentamy et al. 2012) have already underlined that wind speed (and stress) retrieval is very difficult in rainy conditions because of the backscatter of raindrops in the atmospheric column above the surface. The CERSAT version of QuikSCAT data uses the Impact based Multidimensional Histogram method (see Huddleston and Stiles. 2000 for details) for rain flagging. Bentamy et al. (2012) recently demonstrated that their estimation of wind speed could be significantly improved by applying a stricter flagging of rainy situations, but this improved estimate is not available yet. As discussed in the introduction, the wind stress is normally computed as a function of the wind speed relative to the sea surface (i.e. from vector winds minus vector currents). The advantage of satellite scatterometers is that they directly provide an estimate of stress at the ocean surface, and hence naturally account for the effect of currents on wind stress (Bentamy et al. 2003; Chelton and Freilich. 2005).

\section{b. Global Tropical Moored Buoy Array}

The Global Tropical Moored Buoy Array (McPhaden et al. 2010, see Figure 1 for mooring locations) is a multi-national effort providing surface meteorological and subsurface oceanic nearreal time data for research and applications. It has three components, namely TAO/TRITON in the tropical Pacific (McPhaden et al. 1998), PIRATA in the tropical Atlantic (Bourles et al. 2008) and RAMA in the tropical Indian Ocean (McPhaden et al. 2009). Hereafter data from the tropical moored array will be referred to as TPR data (for TAO/TRITON-PIRATA-RAMA).

Moorings from the TPR network measure wind speed at about 4m-height and air temperature and humidity at 3m-height. Wind stresses are computed from the telemetered daily average zonal and meridional winds, using the COARE v3.0 algorithm, as described in Cronin et al. (2006), and are

available from the TAO Project $\quad$ OceanSITES page (http://www.pmel.noaa.gov/tao/OceanSITES/index.html). A diurnal gustiness factor, computed at 
each site from higher frequency wind data when available, is used to account for wind variations shorter than one day, similar to the approach described in Cronin et al. (2006). The TPR wind stresses are computed both from absolute wind velocity and relative wind velocities when surface layer (typically at $10 \mathrm{~m}$ depth) currents are available from the moorings. Since surface layer currents are less frequently available than other meteorological parameters, the TPR relative stress database is not as complete as the absolute one (only $1 / 5^{\text {th }}$ of data compared to the absolute stress database). As demonstrated in the TPR fluxes documentation http://www.pmel.noaa.gov/tao/oceansites/flux/documentation.html), the TPR absolute and relative wind stresses are very similar (0.99 correlation, less than $0.006 \mathrm{Nm}^{-2}$ rmd-difference in wind stress norm over the entire dataset). Hence, unless otherwise specified, we use the larger absolute wind stress database in the rest of the paper.

TPR data undergo stringent quality control procedures to ensure high accuracy standards (Freitag et al. 1999, 2001, Medavaya et al. 2002, Payne et al. 2002, Lake et al. 2003). We only use daily wind stress data with quality flags one and two (highest or default quality) when evaluating other products. Figure 1a shows the total number of valid data for the entire QuikSCAT record (20 July 1999 to 13 October 2009), the shortest record among the wind stress products we analyze. TAO/TRITON is the first mooring array that was initiated (Figure 1b), and most moorings over the Pacific Ocean have between 5 and 10 years of daily data over the QuikSCAT period. The PIRATA array was the next one to be deployed (Figure 1b), and most moorings provide 2 to 7 years of data. The shortest records are in the Indian Ocean (Figure 1b), with no mooring exceeding a total of 3 years of valid data. The number of high quality daily observations from the TPR array is quite stable (around 50) since 1999.

The statistics in the paper are shown for comparison of 5-day averaged TPR and re-analysis data valid at the same time. This 5-day averaging was introduced to avoid giving too much weight to very high frequency wind variations. Note, however, that qualitatively very similar conclusions are obtained when computing statistics from daily data. Most statistics presented in this paper were computed over a common period of 1 August 1999 - 31 July 2009, which includes the entire QuikSCAT period, except for a few months near the beginning and end of the QuikSCAT record so that we retain exactly 11 full seasonal cycles. From now on, the "QuikSCAT period” refers to this 11-years long evaluation period.

The overall statistics mentioned above do not distinguish the ability of various datasets to reproduce observed variability at different time scales (intraseasonal, seasonal, interannual variability 
etc.). We thus also provide statistics for each of these timescales. The TPR intraseasonal variability is defined here as 10-90 day filtered data using a 101-point digital filter. This 10-90 day window was chosen because it includes both MJO timescales (most energetic between 20 and 80 days, e.g. Wheeler and Hendon 2004) and westerly wind bursts, which play an important role in El Niño onset, and have typical durations of 10-20 days (e.g. Lengaigne et al. 2004). This procedure causes $\sim 50$ days of data to be lost on both ends of any segment of uninterrupted data. We computed the TPR mooring seasonal cycle by fitting the first 3 harmonics of the annual cycle (365, 182.5 and 121.7 days) to any mooring with more than 5 years of data. The interannual anomalies are defined as 90day low passed filtered differences between TPR original data and the fitted seasonal cycle (data are also lost on both sides of any segment of data due to filtering). We provide statistics for intraseasonal / seasonal / interannual variability only for those moorings with more than 1 / 4 / 7 years of valid data. This means that, while we can evaluate intraseasonal variations in the three tropical oceans, we can only evaluate the mean seasonal cycle in the Atlantic and Pacific, and interannual variability in the Pacific.

While they provide valuable data against which to compare re-analyses, TPR data do not provide a fully independent validation. The TPR data are assimilated in most of the re-analysis products. We will hence talk about "evaluation” when comparing various datasets to the dependent TPR data, and about "validation” when using the independent OceanSITES dataset discussed below.

\section{c. Independent validation data sets}

Since comparison with TPR observations provides only partially independent evaluation, we also use data from five mooring locations collected over the last two decades by Woods Hole Oceanographic Institution (WHOI). These datasets are withheld from operational data streams and hence provide a completely independent dataset for re-analyses validation purposes. The five moorings are from: Arabian Sea experiment (Arabian Sea Mixed Layer Dynamics Experiment; Weller et al. 1998), COARE experiment (Coupled Ocean-Atmosphere Response Experiment; Webster and Lukas 1992), WHOTS experiment (WHOI Hawaii Ocean Time series Station Experiment; Plueddemann et al. 2006; Whelan et al. 2007), Stratus experiment (Colbo and Weller 2007) and the Subduction experiment (Brink et al. 1995). These locations are shown as black asterisks in Figure 1.

These moorings provide high quality, hourly meteorological and oceanographic data over periods ranging from a few months to a few years. We use these data to produce hourly time series of wind stresses using COARE v3.0 (Fairall et al. 1996, 2003) algorithm. We apply no gustiness 
correction other than the one built in the COARE v3.0 algorithm in this computation, and obtain daily wind stresses from the hourly values. Note that, we neglected surface currents (which are not always available) while computing wind stresses at these moorings.

\section{The TropFlux wind stress product}

In this section, we first present the methodology for computing TropFlux momentum fluxes. Since those rely heavily upon ERA-I data, we then present a comparison of TropFlux and ERA-I to TPR data, to investigate the added value of TropFlux.

\section{a. Estimation method}

The TropFlux project aims at producing high quality daily, timely heat and momentum fluxes over the tropical oceans. The companion paper by Praveen Kumar et al. (2012) describes the development of TropFlux heat fluxes and shows that, together with OAFlux heat fluxes (Yu and Weller 2007), it compares best to TPR and OceanSITES data. In this section, we present the methodology of TropFlux wind stress computation, largely derived from Praveen Kumar et al. (2012). TropFlux wind stresses are available at $1^{\circ} \mathrm{x} 1^{\circ}$, daily resolution within $30^{\circ} \mathrm{S}-30^{\circ} \mathrm{N}$ from 1979 to almost near real time from http://www.locean-ipsl.upmc.fr/tropflux or http://www.nio.org.

We use the strategy of Cronin et al. (2006) for computing wind stresses:

$$
\begin{aligned}
& \tau=\rho_{a} C_{d} s^{2} \\
& s=\left(w^{2}+w_{g}{ }^{2}\right)^{1 / 2}
\end{aligned}
$$

where $\tau$ is the estimated daily wind stress magnitude, $\rho_{a}$ surface air density, $C_{d}$ the drag coefficient computed by the COARE v3.0 algorithm (as a function of sea surface temperature, 2m-air temperature and humidity, 10m-wind), $w$ the daily-average wind speed and $w_{g}$ a climatological diurnal gustiness. The climatological gustiness $w_{g}$ is calculated following Praveen Kumar et al. (2012) as a function of long term-mean SST, with the mean relation between gustiness and SST derived from the gustiness at each TPR site computed as in Cronin et al. (2006). Following the TPR methodology, the zonal and meridional components of momentum flux are obtained as:

$$
\begin{aligned}
& \tau_{x}=\tau(u / s) \\
& \tau_{y}=\tau(v / s)
\end{aligned}
$$

where $\mathrm{u}$ and $\mathrm{v}$ are the $10 \mathrm{~m}$-wind daily average zonal and meridional components. 
The basic input variables necessary to compute wind stresses using this strategy are hence the 2m-air temperature and humidity, 10m-wind and SST. Detailed evaluation of these variables against TPR observations suggests that ERA-I performs better than other sources of data but with some caveats such as systematic biases and reduced variability (see Figure 3 of Praveen Kumar et al. 2012). We hence use here the same bias and amplitude correction strategy as in Praveen Kumar et al. (2012). Briefly, all ERA-I variables are corrected from a spatially homogenous long-term bias estimated from TPR data, except temperature for which a spatially dependent bias is applied as a function of climatological air temperature. All variables are also multiplied by a constant coefficient fitted on TPR data. For wind speed, the correction is obtained as $w_{c}=\left[1.11 w^{\prime}+\left(w_{m}+0.28\right)\right]$ with units in $\mathrm{ms}^{-1}$, where $w_{m}$ is the long term mean and $w^{\prime}$ is the anomaly with respect to long term mean. We use this corrected wind speed to compute $s$ from equation 2, and then use this $s$ in equations (1), (3) and (4).

As indicated by equations (1) or (2), we use absolute winds when computing surface wind stresses, and hence do not account for the effect of surface currents. There are two additional options to account for the effect of surface waves on the wind stress estimate in Fairall et al. (2003): we did not use them in the current TropFlux wind stress estimates. We will discuss the effect of those approximations in the discussion section.

\section{b. TropFlux vs. ERA-I wind stresses}

TropFlux momentum fluxes are largely derived from ERA-I. In this subsection, we compare TropFlux and ERA-I to TPR data in order to evaluate the added value of the TropFlux product. We show statistics for the wind stress modulus, but the same conclusions can be drawn for the zonal and meridional components (not shown).

TropFlux differs from ERA-I momentum fluxes in the following ways:

1) ERA-I momentum fluxes are retrieved from forecast average wind-stress whereas TropFlux stresses are computed from the analyzed winds (and $2 \mathrm{~m}$ temperature and humidity) using a bulk formula. The boundary layer scheme used in ERA-I has a formulation in essence very similar to the COARE v3.0 algorithm (A. Beljaars, personal communication, 2012), so that this part of the difference should be dominated by differences in analyzed / forecast wind speed, more than the $C_{\mathrm{d}}$ formulation in equation (1).

2) Analyzed ERA-I variables are bias and amplitude corrected before fluxes are 
computed

3) We apply a gustiness correction to account for unresolved subdiurnal wind variations.

In order to evaluate separately the influence of 1-3, Figure 2 shows TPR evaluation statistics for the extracted ERA-I wind stresses (ERA-I), for wind stresses computed from the analyzed winds (ANA), from the analyzed winds with amplitude and bias correction (COR), from the analyzed winds with gustiness applied (GUST) and for TropFlux (See Figure caption for details).

ERA-I wind stresses display very good phase agreement with TPR data (0.93 correlation, Figure 2a) and negligible mean bias (Figure $2 \mathrm{~d}$ ) but underestimate variability by $~ 10 \%$ (Figure 2c). Re-computing wind stresses from the analysis rather than the forecasts slightly improves the phase agreement, but further diminishes the amplitude of wind stress variability, and results in a negative wind stress bias. Applying the gustiness correction reduces the mean bias, down to $\sim 7 \%$ of the mean TPR value. Applying the wind correction reduces both the bias and improves the variability amplitude. Applying both the gustiness and wind correction together results in both a weak positive bias and amplitude of variability close to TPR data. Note that applying the gustiness does not clearly improve TropFlux stresses compared to COR. However, the same approach resulted in a notable improvement in the mean net heat flux bias values in Praveen Kumar et al. (2012). Hence for consistency, we keep the same approach for the wind stress computation here.

While TropFlux is marginally better than ERA-I in terms of its correlation and amplitude ratio to TPR stresses, its rms-error is 17\% smaller than that of ERA-I (Figure 2b). While Figure 2 provides an assessment of the overall improvement brought by TropFlux over the entire TPR array, Figure 3 provides a systematic comparison of TropFlux and ERA-I evaluation statistics at each TPR mooring (and at each independent OceanSITES mooring). TropFlux corrections have a positive impact on the correlation and rms-error to mooring data at almost all sites (Fig. 3a and 3d). The amplitude of the TropFlux wind stress variability is closer to mooring data at 61 sites out of 90 (Fig. 3c). The mean bias is reduced at 47 sites out of 90 (Fig. 3d), with TropFlux having a tendency to increase the bias in western Pacific.

The TropFlux approach is hence successful in adding value to ERA-I wind stresses. The improvement of TropFlux wind-stresses against ERA-I is however not as significant as the improvement we obtained on net heat fluxes (Praveen Kumar et al. 2012) mainly because ERA-I wind stresses were already very good, especially in terms of phase agreement and mean bias. 


\section{Evaluation of the stress products}

In this section, we evaluate NCEP, NCEP2, ERA-I, TropFlux and QuikSCAT wind stresses from various sources against TPR mooring buoy observations. We then provide a completely independent validation against observations from five OceanSITES mooring locations. We discuss differences in climatological wind stress, before focusing on a dynamically important region: the equatorial band.

\section{a. Evaluation against TPR data}

Figure 4 shows overall statistics for the comparison of various products against TPR wind stress data. These statistics are evaluated over 1 August 1999 - 31 July 2009, the longest common period with QuikSCAT. We show statistics for the wind stress magnitude, but statistics for zonal and meridional components display very similar features (the only exception is that QuikSCAT meridional wind stress component is generally more accurate than the zonal component). NCEP and QuikSCAT display the largest bias in terms of mean state (Fig. 4b) and std ratio (Fig. 4c) with opposite tendencies. NCEP underestimates the amplitude of TPR wind stress variability by $24 \%$ while QuikSCAT overestimates it by 17\%. NCEP also tends to display a strong negative mean bias (19\% of the mean TPR value), while QuikSCAT displays a strong positive bias (28\% of the mean TPR value). These results are generally consistent with previous studies discussing NCEP (Josey and Taylor. 2002; Meissner et al. 2001) and QuikSCAT accuracy (e.g., Satheesan et al. 2007; Jiang et al. 2005). In contrast, NCEP2 and ERA-I capture the amplitude of wind stress variability better along with its mean value. ERA-I however displays a far better phase agreement (0.93 correlation) than NCEP and NCEP2 (0.83).

Figure 4 hence illustrates that ERA-I data is overall the best re-analysis product. Despite this enviable property, ERA-I still underestimates the variability by about 9\% (Fig. 4c). This supports the choices we made in Praveen Kumar et al. (2012): 1) select ERA-I as TropFlux input data; 2) but apply a bias and amplitude correction. The TropFlux dataset captures the variability remarkably well with the highest correlation / lowest-rms difference to TPR data $\left(0.95 / 0.01 \mathrm{Nm}^{-2}\right)$. It has a weak mean bias ( $2 \%$ of the mean TPR data), and captures the amplitude fairly well ( $\sim \%$ underestimation of the variability).

Statistics in Figure 4 provide an overall evaluation of TropFlux for all TPR sites taken collectively. Figure 5 allows a more regional view. The color of the marker gives the correlation and rms-difference of TropFlux to TPR data. Square markers indicate locations where TropFlux 
outperforms all other products (i.e. highest correlation for upper panels and lowest rms-difference for lower panels). TropFlux displays the highest correlation and the lowest rms-difference to TPR data at most sites, both for zonal and meridional wind stresses. This analysis suggests that TropFlux not only displays the best overall agreement with TPR data, but also generally agrees best at individual locations.

The overall correlation of net heat flux to TPR data ranges from 0.54 (NCEP and NCEP2) to 0.87 (TropFlux) (Praveen Kumar et al. 2012). Our results clearly show that the agreement of wind stress products to TPR data is generally better than for net heat flux, with correlations ranging from 0.82 (NCEP2 and QuikSCAT) to 0.95 (TropFlux).

\section{b. Comparison of TropFlux and QuikSCAT products}

The evaluation presented above is quite local in space. In order to provide an assessment in the entire tropical band, background colors in Figure 5 show correlations and rms-differences of TropFlux to QuikSCAT wind stresses, over the QuikSCAT period. While QuikSCAT is not a direct measurement (and relies on inversion of a backscatter signal), its high quality has been underlined many times (e.g. Figure 3 in Praveen Kumar et al. 2012, shows that QuikSCAT winds, despite some overestimation, generally compare well to TPR data).

Left panels of Figure 5 show a strong disagreement of TropFlux and QuikSCAT zonal wind stresses along Intertropical Convergence Zones (ITCZ) of the three tropical oceans, and to a lesser extent in the South Pacific Convergence Zone (SPCZ). At those locations, comparison with TPR data display much more favourable statistics for TropFlux (markers on Figs. 5a and c). As already mentioned, numerous studies already illustrate the inability of QuikSCAT to satisfactorily capture wind in rainy regions (Milliff et al. 2004; Gille et al. 2005; Bentamy et al. 2012) due to backscatter of the radar signal by rain drops in the atmospheric column. Other authors (Bentamy et al. 2003; Chelton and Freilich 2005) however argue that scatterometers have the advantage of directly providing an estimate of stress at the ocean surface, hence naturally accounting for the influence of ocean currents on surface stress. We thus need to evaluate whether differences between TropFlux and QuikSCAT in Figure 5 are the results of rainfall bias in the QuikSCAT product or due to the stationary ocean assumption in the other products, including for TPR at sites that do not carry nearsurface current meters. To that end, Figure 6 shows a scatterplot of the rms-difference (mean, median and quartile values) between TropFlux / QuikSCAT wind stresses and TPR estimates, as a function of the TPR-measured rain rate (Serra et al. 2001) and near-surface current speed. For this plot we used TPR wind stress estimates that account for the effect of surface currents (rather than those based 
on absolute wind speed alone). The QuikSCAT and TropFlux differences with those TPR wind stress were then binned depending on the TPR-measured value of the rain rate (Fig. 6a) or current speed (Fig. 6b). The bin size was defined as $1 / 2$ of the overall standard deviation for both rain and currents.

TropFlux wind stress errors display hardly any dependence on either rain rate (Fig. 6a) or surface currents (Fig. 6b). This indicates that rain or surface currents do not contribute strongly to TropFlux wind stress errors. On the other hand, QuikSCAT wind stress rms-error clearly increases with rain-rates, while this increase is much less obvious as a function of current speed. This is a very clear indication that QuikSCAT differences with mooring-estimated stresses are largely the result of contamination by rainfall, not of the effect of surface currents, consistent with the recent results of Bentamy et al. (2012). In their study, Bentamy et al. (2012) demonstrated that the overall error in QuikSCAT wind retrievals diminishes when a stricter flagging of rain events is applied. These caveats for QuikSCAT hence explain its lower quality in heavy rain regions, when compared with other products.

In most rain-free regions, QuikSCAT and TropFlux wind stresses generally agree reasonably well (with correlations exceeding 0.8 and rms-differences generally below $0.03 \mathrm{Nm}^{-2}$; Fig. 5). This result does not indicate that TropFlux is better or worse than QuikSCAT in these areas, but that the two products are consistent with no obvious flaws away from the area coved by TPR moorings.

\section{c. Independent validation to OceanSITES data}

As we mentioned in section 2c, TPR observations do not provide a completely independent validation because (a) TPR observations are assimilated in various re-analyses and (b) TPR observations are used for deriving ad-hoc corrections while producing the TropFlux product. Data from the OceanSITES network are however neither used in re-analyses nor in the TropFlux generation procedure and hence provide an independent validation. Figure 7 summarizes the validation of wind stress magnitudes at the 5 mooring sites described in section 2c (note that separate validation of the zonal and meridional components generally lead to the same conclusions).

The validation with independent data suggests that: a) NCEP and NCEP2 generally underestimate mean wind stress and its variability (except at the stratus site), while other products have more differentiated behaviours; b) TropFlux has 4 times out of 5 the highest correlation and 3 times out of 5 the lowest rms-difference, c) there is generally (4 times out of 5) a neutral effect or improvement of TropFlux relative to ERA-I although this is not as clear as when gauged against TPR (also see Figure 4). But overall, this validation relative to independent data suggests that TropFlux 
(and ERA-I) products generally provide the most accurate wind stress estimates in the tropics.

\section{d. Differences in mean state}

In this subsection, we briefly discuss climatological differences in wind stress. Figure 8 shows the long-term average wind stress for TropFlux (panel a), and the difference between all the other products and TropFlux (panels b-e). As shown in Figure 8a, easterly winds clearly prevail in the Atlantic, Pacific and Southern Indian Oceans. The western Pacific and Indian Ocean warm-pool exhibit weak long-term mean wind stress. The Northern Indian Ocean annual average clearly exhibits the mark of the Indian Monsoon flow, with a strong Somali jet over the Arabian Sea. ERA-I and TropFlux wind stress climatologies are very similar. In contrast, QuikSCAT tends to be much stronger than TropFlux everywhere, especially in the Pacific ITCZ. NCEP tends to be weaker in the $15^{\circ} \mathrm{N}-15^{\circ} \mathrm{S}$ band and NCEP2 stronger, except in the equatorial Pacific.

Wind stress curl is an important parameter for the ocean forcing outside of the equatorial waveguide. Contrasts between wind stress curl climatology amongst products are illustrated for the central Pacific in Figure 9. In general, all display strong curl towards the center of subtropical gyres (between $20^{\circ}$ and $30^{\circ}$ of latitude), and slightly negative values between the equator and $10^{\circ} \mathrm{S}$. All products display a maximum curl around 8 to $10^{\circ} \mathrm{N}$ associated with the boundary between the North Equatorial Current and North Equatorial Counter Current but with large discrepancies in both structure and amplitude. QuikSCAT has a double maximum structure, unlike any other products, probably related to rain contamination under the ITCZ (as discussed in section 4b) while NCEP maximum is much broader. The structure of maximum curl agrees reasonably well for NCEP2, TropFlux and ERA-I, with larger values for NCEP2 (0.8 instead of $\left.\sim 0.510^{-7} \mathrm{~Pa} \mathrm{~m}^{-1}\right)$.

Within the equatorial waveguide, the important dynamical quantity is zonal wind stress, rather than curl. The slope of the thermocline in the Pacific and Atlantic oceans is indeed to the first order in balance with the climatological zonal wind stress (e.g., McCreary 1981). TPR data allows us to establish which products have the most realistic long-term estimate of wind stresses (Fig. 10) along the equatorial band. NCEP climatological equatorial wind stresses are too weak everywhere in the tropical band. NCEP2 climatological equatorial wind stresses are too weak in the Pacific Ocean, but otherwise in close agreement with TPR. QuikSCAT climatological equatorial zonal wind stresses are overestimated by a large amount in the Indian Ocean and western Atlantic Ocean, but are generally similar to TPR in the Pacific. ERA-I and TropFlux display the best agreement with the TPR longterm average zonal equatorial wind stresses. 


\section{e. Intraseasonal, seasonal and interannual variability along the equatorial band}

Zonal wind stress variations induce very clear ocean response at several timescales in the equatorial waveguide. On interannual timescales, this response is important dynamics in the Pacific Ocean for El Niño (e.g., Boulanger and Menkes 1999; Lengaigne et al. 2006), and in the Indian Ocean for the Indian Ocean Dipole (e.g., Le Blanc and Boulanger 2001). On seasonal time-scales, the Indian Ocean displays a very energetic response to zonal wind stress, with very clear spring and fall jets (Wyrtki 1973). At intraseasonal timescale, there is also a clear modulation of equatorial currents and sea level in the Indian Ocean (e.g., Han et al. 2001; Sengupta et al. 2007; Nagura and McPhaden 2012). In the Pacific Ocean, intraseasonal wind variations induce a clear oceanic response (e.g., Cravatte et al. 2003), and westerly wind bursts (WWBs) in particular can contribute to the western displacement of the warm pool during the El Niño onset (Kessler et al. 1995; Lengaigne et al. 2002, 2004). In this section, we evaluate specifically zonal wind stresses to TPR data at each of those timescales. We define intraseasonal timescales as 10-90 day filtered data in order to retain both the influence of the MJO and WWBs. The seasonal cycle is defined by fitting three harmonics, and the interannual variability is defined as 90-day low-passed differences from the raw signal and the seasonal cycle.

Figure 11 shows intraseasonal statistics of zonal wind stress products along the entire equatorial strip. Observed zonal wind intraseasonal variability is strongest in the eastern Indian Ocean and in the western and Central Pacific (Fig. 11b), while it is comparatively small in the equatorial Atlantic. At this timescale, ERA-I and TropFlux products display the best agreement with TPR variability at almost all locations, both in terms of phase (with correlations $>0.9$ in the region of significant intraseasonal zonal wind stress variability, versus 0.8 at best for other products; Fig. 11a) and amplitude (Fig. 11b). Indeed, QuikSCAT strongly overestimates intraseasonal variability in the Indian Ocean and western Pacific. Both NCEP re-analyses underestimate zonal wind stress variability in the western Pacific (by 20 to 30\%), but only NCEP re-analysis underestimates intraseasonal zonal wind stress variability in the Indian Ocean. The improvement of TropFlux compared to ERA-I, although modest, is systematic in terms of phase and even clearer in terms of amplitude: the TropFlux and TPR intraseasonal wind stress amplitudes match at most locations.

Westerly wind bursts in late 1996 and 1997 were very important in the 1997-1998 El Niño onset and development (e.g., McPhaden 1999; Vialard et al. 2001; Lengaigne et al. 2002, 2003). Figure 12 shows 10-90 day filtered wind stresses from TPR data and other products (except 
QuikSCAT, which was not available yet) at $156^{\circ} \mathrm{E}$ and $165^{\circ} \mathrm{E}$ in late 1996 and 1997 . These longitudes were chosen because they exhibit some of the strongest wind stress variability along the equator. Only TropFlux captures the full magnitude (with slight overestimation) of WWBs during this period (Fig 12). While the March 1997 WWB is reasonably well captured by most products at $165^{\circ} \mathrm{E}$ (Fig 12b), the December 1996 WWB (Fig. 12a) and April-May 1997 WWB (Fig. 12b) are strongly underestimated by the NCEP and NCEP2 re-analyses (by 70\%) and to lesser extend by ERA-I (by 40\%). In contrast, these WWBs are of comparable magnitude to TAO/Triton data in TropFlux.

Figure 13 shows $10-90$ day filtered wind stresses in the eastern Indian Ocean $\left(0^{\circ}, 90^{\circ} \mathrm{E}\right)$. In November 2007 and April 2008, all products show 20 days long westerly anomalies (overestimated by NCEP2 and QuikSCAT), which force a strong intraseasonal pulse of the Wyrtki jet (e.g., Sengupta et al. 2007). QuikSCAT sometimes generate spurious variability, probably due to rainfall contamination (e.g., a very strong spurious burst in December 2007, an overestimated westerly wind event in July 2008, etc.).

Various products display non-negligible differences, mainly in terms of amplitude of the seasonal cycle along the equatorial band (Fig. 14). None of the products match the amplitude of the observed seasonal cycle in the western and Central Pacific; overall amplitude underestimation is $\sim 20-30 \%$, except for QuikSCAT which strongly overestimates the seasonal cycle in the western Pacific Warm Pool. The phase agreement with TPR data is generally very good (correlation > 0.9, except for QuikSCAT and NCEP2 at a few locations). TropFlux and ERA-I are almost always the best products, with TropFlux slightly improving ERA-I seasonal wind stresses.

Figure 15 shows zonal wind stress statistics on interannual time scales at all TAO/TRITON sites along the equator. Largest interannual observed zonal wind stress variability is found over the warm pool between $156^{\circ} \mathrm{E}$ and $180^{\circ} \mathrm{E}$. Over this region, most products display quite good phase agreement with TPR zonal stresses (correlation > 0.9). Most products, except TropFlux and QuikSCAT, tend to underestimate the interannual variability. TropFlux and ERA-I zonal wind stresses have the best interannual variability, with TropFlux displaying better amplitude agreement with TPR. In summary, statistics computed for the entire TPR network and for both components of the wind stresses (not shown) indicate that TropFlux and ERA-I display the best agreement with TPR data for the three timescales (intraseasonal / seasonal / interannual) within the entire tropical region. 


\section{f. Synthesis and comparison with heat fluxes}

We define the following metric, $e$, in order to measure the level of agreement between various products $\mathrm{X}_{\mathrm{i}}^{\mathrm{j}}$ (where $\mathrm{i}$ designates the one of the 5 wind stress products NCEP, NCEP2, ERA-I, TropFlux and QuikSCAT; j designates the 5-days time step):

$$
e=\frac{\frac{1}{I} \sqrt{\sum_{j} \sum_{i}\left(X_{i}^{j}-\overline{X^{j}}-[X]\right)^{2}}}{\sqrt{\sum_{j}\left(\overline{X^{j}}-[X]\right)^{2}}} \text { with } \overline{X^{j}}=\frac{1}{I} \sum_{i} X_{i}^{j} \text { the "ensemble mean" of the I available }
$$

products and $[X]=\frac{1}{I J} \sum_{j} \sum_{i} X_{i}^{j}$ the ensemble average long term mean. The denominator of this expression is the standard deviation of the ensemble average of the 5 products and the numerator is the "ensemble spread", i.e. a root mean square measure of the spread around the ensemble mean $\overline{X^{j}}$. The "relative spread" $e$ is a dimensionless quantity that expresses the typical spread of the products relative to the consensus value provided by the average of all products, and normalized by the variability of this consensus value. Note that this quantity does not measure systematics biases, only differences in variability.

We already noted that the agreement between various wind stress products and TPR data is in general better than for net heat fluxes discussed in Praveen Kumar et al. (2012) (correlations of 0.80.95 for wind stresses against 0.5-0.85 for heat fluxes). Figure 16 allows a quantitative comparison of the "relative spread" $e$ of the 5 wind stress products in this study with the "relative spread" of the 5 net heat flux products in Praveen Kumar et al. (2012). Since the definition of this measure is relative to the amplitude of variability, both wind stress and net heat fluxes display stronger spread of values near the equator, where air-sea momentum and heat fluxes vary less, than toward mid latitudes (Fig. 16). Because of previously discussed issues related to the wind stress retrieval in intense rainfall regions, QuikSCAT is often an outlier under the ITCZ in the Pacific and Atlantic Oceans, and in the western Pacific and eastern Indian Ocean warm pool. As a result, Figure 16a shows a large spread under intense rainfall regions. This spread is strongly reduced when QuikSCAT is excluded from the spread computation (compare Figure 16a and 16b; no equivalent reduction in spread is obtained when any other product is excluded). The normalized wind stress spread in Figure $16 \mathrm{~b}$ is overall clearly smaller than the spread of net heat fluxes (Figure 16c, the zonal average flux spread is $\sim 0.85$ at the equator and $\sim 0.4$ poleward of $15^{\circ}$ versus $\sim 0.55$ and 0.3 , respectively, for wind stress). This indicates that wind stress products agree better amongst themselves than net heat flux 
products. We will discuss this further in section 5.

\section{Summary and Discussion}

\section{a. Summary}

This paper is part of our ongoing effort to provide timely and accurate daily fluxes of heat and momentum over the global tropical oceans. We presented the TropFlux heat flux data in Praveen Kumar et al. (2012). Here, we present TropFlux wind stresses, available at $1^{\circ} \mathrm{x} 1^{\circ}$, daily resolution within $30^{\circ} \mathrm{S}-30^{\circ} \mathrm{N}$ from 1979 to almost near real time, from http://www.locean-ipsl.upmc.fr/tropflux and http://www.nio.org. Following Praveen Kumar et al. (2012), TropFlux wind stresses are computed by applying the COARE v3.0 algorithm to bias and amplitude corrected ERA-I data. A gustiness correction is also applied to wind speed on the basis of climatological SST, in order to account for unresolved (meso-scale, diurnal and subdiurnal) wind variations by the ERA-I dataset.

The resulting wind stresses as well as three other timely, daily re-analyses (ERA-I, NCEP and NCEP2), and the widely used QuikSCAT 1999-2009 wind stresses, are evaluated against dependent data from the TAO/TRITON, PIRATA and RAMA and independent OceanSITES mooring networks. Wind stress products are more consistent amongst each other than surface heat fluxes, suggesting 10m-winds are better constrained than near-surface thermodynamical parameters (2mhumidity and temperature) and surface downward radiative fluxes. NCEP, NCEP2 and QuikSCAT wind stresses display equivalent overall performance relative to TPR data (correlations of 0.81 to 0.84 and rms-differences of 0.021 to $0.026 \mathrm{Nm}^{-2}$ ). QuikSCAT overestimates wind stresses away from the equator, while NCEP and NCEP2 underestimate wind stresses. QuikSCAT zonal wind stress quality is strongly affected by rain under the ITCZ. Both ERA-I and TropFlux display the best agreement with in-situ data, with correlations $>0.93$ and rms-differences $<0.012 \mathrm{Nm}^{-2}$. The TropFlux wind stresses exhibit a small, but consistent improvement (at various timescales and most locations) over ERA-I, with an overall 17\% reduction in rms-error.

We further investigate equatorial zonal wind stresses in detail, owing to their importance for forced ocean dynamical responses. NCEP climatological equatorial wind stresses are too weak everywhere in the tropical band. NCEP2 climatological equatorial wind stresses are too weak in the Pacific Ocean, but otherwise in good agreement with TPR. QuikSCAT climatological equatorial zonal wind stresses are overestimated by a large amount in the Indian Ocean and western Atlantic Ocean, but are generally more accurate in the Pacific. ERA-I and TropFlux display the best agreement with the TPR long-term average zonal equatorial wind stresses. All products tend to 
underestimate the zonal wind stress seasonal cycle by $20 \%$ in the western and central Equatorial Pacific. Consistent with the overall statistics discussed earlier, TropFlux and ERA-I equatorial zonal wind stresses have clearly the best phase agreement to TPR data at intraseasonal and interannual timescales (correlation of $\sim 0.9$ versus $\sim 0.8$ at best for any other product), with TropFlux correcting the $\sim 13 \%$ underestimation of ERA-I variability amplitude at both timescales.

While overall statistics indicate almost identical performances of ERA-I and TropFlux, these two products display significant differences on an event-to-event basis. For example, various products display important differences in reproducing the late 1996 and 1997 westerly wind bursts that played a key role in the 1997-98 El Niño onset and development, with TropFlux displaying the best agreement to TPR data.

Finally, Table 1 provides a quantitative estimate of the rms-errors of TropFlux with respect to TPR data: $0.009 \mathrm{Nm}^{-2}$ for five-day averaged data, a value that does not vary strongly depending on the basin. The average root-mean-square wind stress magnitude at all TPR sites is $0.061 \mathrm{Nm}^{-2}$ for both TPR and TropFlux. This provides a relative measure of the uncertainty in the TropFlux wind stress product: $0.009 / 0.061$, i.e. a 15\% error arising from sampling and observational uncertainties. This number can be compared with the 5-10\% accuracy of the COARE algorithm quoted by Fairall et al. (2003). If instrumental and sampling errors are assumed to be independent from errors arising from the use of a bulk transfer coefficient, the typical error on the 5-day averaged TropFlux wind stress estimates is hence below $20 \%$, and mostly arises from wind and sampling uncertainties.

\section{b. Discussion and perspectives}

This study suffers from the same limitation as that of Praveen Kumar et al. (2012). First, we use dependent data from the TPR array extensively and so our evaluation is more a check on the ability of the various products to fit the observations than a true independent validation. We do, however, believe that the most serious issue associated with the use of these data is the fact that our analysis is most complete in the well-sampled $10^{\circ} \mathrm{N}-10^{\circ} \mathrm{S}$ latitude band best sampled by the TPR array: we trust our evaluation of the various products within this band, but it is probably less representative of the $10^{\circ}-30^{\circ}$ band.

Another limitation of our study is that we rely on the TPR wind stress estimates, and hence on the COARE v3.0 algorithm, and the gustiness approach proposed by Cronin et al. (2006). COARE has been developed specifically for tropical regions and Fairall et al. (2003) claim a 5 to 10\%

accuracy of the COARE algorithm for winds up to $20 \mathrm{~ms}^{-1}$. In addition, the gustiness approach 
proposed by Cronin et al. (2006) (but applied here over the entire TPR array) is based on actual climatological differences between wind speeds estimated from daily averages, and wind speeds estimated from high frequency (10 minutes) data. One of the limitations of our approach, however, is that this application of the gustiness is climatological, and does not take into account non-seasonal variations of the convective and meso-scale variability.

Another possible limitation of our method is that we neither account for the effect of surface waves nor surface currents in the computation of the wind stress (surface waves act mainly by modifying the ocean's surface roughness, and surface currents by influencing the relative speed of air with respect to the sea). Some studies have pointed out that the effect of currents and waves may not be negligible for wind stress estimates (e.g. Dawe et al. 2006; Kara et al. 2007). We however feel that our approximations do not cause large errors in the TropFlux dataset. Regarding the effect of surface currents, the TPR product accounts for the effect of surface currents when available and Figure 6 clearly shows that large observed surface currents are not a source of large error in TropFlux compared to TPR. The situation is more difficult regarding surface waves. We don't have available in situ wave characteristics estimates at TPR mooring sites to evaluate the effect of waves from in situ data. Fairall et al. (2003) however noted that "the wave stress community lacked consensus on how to handle waves" when estimating wind stress. Despite those two difficulties, we have two hints that the effects of waves may not be of first-order importance in the tropics. First, ERA-I stresses include explicitly the effect of waves on stress through an interactive wave model, and ERA-I wind stresses are not very different from TropFlux. Second, the COARE v3.0 algorithm includes two parameterizations of the effect of waves (Oost et al 2002, Yelland and Taylor 2001) as a function of the dominant wave period (Oost et al. 2002) and of significant wave height (Yelland and Taylor, 2001), both of which we obtained from the ERA-I re-analysis. Re-computing the TropFlux product with those two estimates yields differences that are typically smaller than the differences between TropFlux and most other products (NCEP, NCEP2, QuikSCAT, not shown). We have hence not included these wave parameterizations in the current TropFlux product, but we recognize the need for a more thorough investigation of the effects of surface waves and surface currents in a future study. While these two effects are generally not large in the equatorial strip, they may be non negligible in strong surface currents and very strong wind conditions, as, e.g. in the western Arabian Sea during the monsoon (e.g. Schott and McCreary. 2001) or in intense tropical storms.

Results from other studies assessing wind stress are generally consistent with ours. Jiang et al. (2005) compare various wind speed products with TPR data, and find consistent results: NCEP and 
NCEP2 tend to underestimate wind speed, and QuikSCAT tends to overestimate it away from the equator. Jiang et al. (2008) compare an ocean general circulation model forced by NCEP2 and QuikSCAT wind stresses. They show an improvement of the model mean state when QuikSCAT wind stresses are used, but no discernable improvement of intraseasonal SST and thermocline depth variations. This last result is qualitatively consistent with the results of Figure 11, which indicate a comparable correlation of NCEP2 and QuikSCAT to TPR data at intraseasonal timescale. Meissner et al. (2001) and Josey and Taylor (2002) also indicate that NCEP wind stresses tend to be underestimated in the tropical region. Studies by Chelton and Freilich (2005), Millif et al. (2004), Gille et al. (2005), Bentamy et al. (2012) also point to a tendency of QuikSCAT to overestimate winds (and wind stresses) and indicate deficiencies of this dataset in intense rainfall regions.

Our results outline some issues with the use of QuikSCAT wind stress data in rainy regions (where it clearly appears as an outlier amongst the products, see Figures 16 and 10). Scatterometer data is still useful though. Many re-analyses and operational products assimilate scatterometer data, with appropriate bias correction and flagging of incorrect data, and this contributes to improving the estimation of surface wind stress (e.g. Chelton et al. 2006), especially in the many oceanic regions where no other direct information on surface wind is available. In addition, the QuikSCAT wind stresses are often of superior quality to some re-analyses (NCEP and NCEP2) away from rainy regions. Many studies of ocean dynamical response to wind stress forcing however use QuikSCAT wind stresses (e.g. Sengupta et al. 2007, Nagura and McPhaden 2010ab; Cravatte et al. 2007; Jiang et al. 2009, amongst many others). We note that, for studies of equatorial ocean dynamics, the ERA-I or TropFlux wind stress forcing are however more appropriate, because they resolve intraseasonal and interannual variability much better in the important forcing regions (e.g. the eastern Indian Ocean and western Pacific), and do not suffer from rainfall contamination as does QuikSCAT.

Our results indicate that wind stresses are generally better constrained than heat fluxes (less spread amongst products, and better consistency with mooring data). This can probably be explained by the fact that wind stress computation largely relies on $10 \mathrm{~m}$ wind estimation (2m-temperature and humidity only have a weak impact, through the drag coefficient computation), which are better constrained by the observing system than surface thermodynamical parameters. Scatterometers indeed provide wide-coverage information about surface winds, while there is no equivalent data for surface humidity and temperature. In addition, wind is also constrained by numerous pressure measurements through geostrophic balance constraints in assimilation systems. As a result, winds suffer from relatively lower systematic biases than surface temperature and humidity (Praveen Kumar et al. 2012). Finally, surface radiative fluxes are a strong source of error in net surface heat 
fluxes (Praveen Kumar et al. 2012). This is probably due to the fact that, while assimilation systems assimilate Outgoing Longwave Radiation (i.e. longwave emission at the top of the atmosphere), they do not impose much constraint on the surface heat budget.

One obvious application of surface heat and wind stress products is to force ocean models. The current study suggests that for tropical studies, the ERA-I and TropFlux data provide very high quality wind stresses and, depending on the particular application, should be preferred to other possibilities. As far as net heat fluxes are concerned, Praveen Kumar et al. (2012) however underlined the ERA-I systematic biases (too strong oceanic heat losses by $\sim 15 \mathrm{Wm}^{-2}$ ), and errors in shortwave fluxes (resulting in an overall correlation to TPR of $\sim 0.75$ against $\sim 0.83$ for TropFlux net heat fluxes). Studies also concerned with thermodynamical response of the tropical ocean should hence use TropFlux fluxes, or apply correction strategies similar to those implemented in the Drakkar Forcing Set (Brodeau et al. 2010).

The TropFlux surface meteorological parameters, surface heat fluxes and wind stress data are available on the TropFlux website at http://www.locean-ipsl.upmc.fr/tropflux from 1979 to nearly the present with daily resolution on a $1^{\circ}$ grid. We are currently working to automatically update TropFlux heat and momentum fluxes so that they are no more than 4 months delayed from the present. We hope that our efforts to develop a better heat and momentum flux product for the tropical oceans will lead to new insights into tropical ocean-atmosphere interactions and tropical climate variability.

Acknowledgements: The development of TropFlux product is the result of a joint research collaboration between National Institute of Oceanography (CSIR/NIO, Goa, India), Institut de Recherche pour le Développement (IRD, France), Institute Pierre et Simon Laplace (IPSL, Paris, France) and Pacific Marine Environmental Laboratory (NOAA/PMEL, Seattle, Washington). BPK and VSNM thank Director, National Institute of Oceanography, India, for his keen interest in this study. The lead author is supported by a Senior Research Fellowship (SRF) from Council of Scientific and Industrial Research (CSIR, Govt. of India) and a one-year research grant from Institut de Recherche pour le Développement (IRD, France) and did part of this work whilst at Laboratoire d'Océanographie Expérimentation et Approches Numériques (LOCEAN, Paris). JV and ML are funded by Institut de Recherche pour le Développement (IRD) and did this work while visiting National Institute of Oceanography (NIO, India). MJM is supported by NOAA. NOAA's Climate Program Office provided support for the calculation of the TPR fluxes. We sincerely thank the providers of NCEP and NCEP2 re-analyses data (NOAA/OAR/ESRL PSD, Boulder, Colorado, 
USA), ERA-Interim (European Centre for Medium Range Weather Forecasting, Reading, United Kingdom), QuikSCAT winds (CERSAT-IFREMER, Brest, France). The mooring data were made freely available by the TAO-PIRATA-RAMA (PMEL-NOAA, Seattle, USA) and OceanSITES international projects, and the national programs that contribute to them. Discussions with A. Beljars (ECMWF) on drag coefficient provided useful inputs. A. Bentamy (IFREMER, France) and W. Ebisuzaki (NOAA, USA) provided useful discussions on wind-wave corrections. Critical comments from two anonymous reviewers greatly helped to improve an earlier version of the manuscript and we acknowledge that. This is NIO contribution number $\mathrm{xxxx}$ and PMEL contribution number 3783.

\section{References}

Annamalai, H., R. Murtugudde, J. Potemra, S.P. Xie, P. Liu, and B. Wang, 2003: Coupled dynamics over the Indian Ocean: Spring initiation of the zonal mode. Deep Sea Research II,50, 23052330.

Bentamy, A., Y. Quilfen, F. Gohin, N. Grima, M. Lenaour et J. Servain, 1996 : Determination and validation of average wind fields from ERS-1 scatterometer measurements. The Global atmosphere and ocean system, 4, 1-29.

Bentamy, A., K B. Katsaros, M. Alberto, W. M. Drennan, E. B. Forde, 2002: Daily surface wind fields produced by merged satellite data. American Geophys. Union, Geophysical Monograph Series, 127, 343-349.

Bentamy, A., K. B. Katsaros, A. M. Mestas-Nuñez, W. M. Drennan, E. B. Forde, and H. Roquet, 2003: Satellite estimates of wind speed and latent heat flux over the global oceans. J. Climate, 16, 637-656.

Bentamy, A., S. A. Grodsky, J. A. Carton, D. Croizé-Fillon, and B. Chapron, 2012 : Matching ASCAT and QuikSCAT winds, J. Geophys. Res., 117, C02011, doi:10.1029/2011JC007479.

Bjerknes. J., 1966: A possible response of the atmospheric Hadley circulation to equatorial anomalies of ocean temperature, Tellus, 18, 820-829.

Boulanger, J-P., and C. Menkes, 1999: Long equatorial wave reflection in the Pacific Ocean from TOPEX/POSEIDON data during the 1992-1998 period, Clim. Dyn., 15, 205-225.

Bourlès, B., R. Lumpkin, M. J. McPhaden, F. Hernandez, P. Nobre, E. Campos, L. Yu, S. Planton, A. J. Busalacchi, A. D. Moura, J. Servaom, and J. Trotte, 2008: The PIRATA Program : History, Accomplishments and Future Directions, Bull. Am. Meteorol. Soc., 89, 1111-1125.

Brink, N. J., K. A. Moyer, R. P. Trask, and R. A. Weller, 1995: The Subduction Experiment: Mooring Field Program and Data Summary. Woods Hole Oceanographic Institution. WHOI95-08, 113 pp.

Brodeau L, B. Barnier, T. Penduff, A. M. Treguier, S. Gulev, 2010: An ERA-40 based atmospheric forcing for global ocean circulation models. Ocean Modelling, 31, 88-104, doi:10.1016/j.ocemod.2009.10.005 
Bruke, M. A., C. W. Fairall, X. Zeng, L. Eymard, J. A. Curry, 2003: Which Bulk Aerodynamic algorithms are Least Problematic in Computing Ocean Surface Turbulent Fluxes ?. J. Clim. 16:4, 619-635

Bunker, A. F., 1976: Computations of surface energy flux and annual air-sea interaction cycles of the north Atlantic, Mon. Wea. Rev., 104, 1122-1140.

Cassou, C., 2008, Intraseasonal interaction between the Madden-Julian Oscillation and the North Atlantic Oscillation, Nature, 455, 523-527.

Chelton, D. B, and M. H. Freilich, 2005: Scatterometer based assessment of 10-m wind analyses from the operational ECMWF and NCEP numerical weather prediction models. Mon. Wea. Rev., 133, 409-429.

Chelton, D. B., M. H. Freilich, J. M. Sienkiewicz, and J. M. Von Ahn, 2006: On the use of QuikSCAT scatterometer measurements of surface winds for marine weather prediction. Mon. Wea. Rev., 134, 2055-2071.

Colbo, K., and R. Weller, 2007: The variability and heat budget of the upper ocean under the ChilePeru stratus, J. Mar. Res, 65, 607-637.

Cravatte, S., J. Picaut, and G. Eldin, 2003: Second and first baroclinic Kelvin modes in the equatorial Pacific at intraseasonal timescales, J. Geophys. Res., 108, 3266, doi:10.1029/2002JC001511.

Cravatte S, G. Madec, T. Izumo, C. Menkes, and A. Bozec, 2007 : Progress in the 3-D circulation of the eastern equatorial Pacific in a climate ocean model. Ocean Modelling, 17, 28-48.

Cronin, M. F., C. Fairall, and M. J. McPhaden, 2006: An assessment of buoy-derived and numerical weather prediction surface heat fluxes in the tropical Pacific. J. Geophys, Res, 111, C06038, doi:10.1029/2005JC003324.

da Silva, A. M., C. C. Young, and S. Levitus, 1994: Algorithms and Procedures. Vol. 1,. Atlas of Surface Marine Data. NOAA Atlas NESDIS 6, 74 pp.

Dawe., J.T. and L. Thompson, 2006: Effect of ocean surface currents on wind stress, heat flux, and wind power input to the ocean, Geophys. Res. Lett., 33, L09604, doi:10.1029/2006GL025784

Dee et al, 2011: The ERA-Interim reanalysis: configuration and performance of the data assimilation system. Q. J. R. Meteorol. Soc., 137: 553 597. doi: 10.1002/qj.828.

Drushka. K., J. Sprintall, S. T. Gille and W. Wijffels, 2011 : In-situ observations of Madden-Julian Oscillation mixed layer dynamics in the Indian and Western Pacific Oceans, J. Clim., doi: 10.1175/JCLI-D-11-00203.1

Duvel, J-P. and J. Vialard, 2007, Indo-Pacific Sea Surface Temperature Perturbations Associated with Intraseasonal Oscillations of the Tropical Convection, J. Clim., 20, 3056-3082.

Fairall, C. W., E. F. Bradley, D. P. Rogers, J. B. Edson, and G. S. Young, 1996: Bulk parameterization of air-sea fluxes for Tropical Ocean-Global Atmosphere Coupled OceanAtmosphere Response Experiment. J. Geophys. Res., 101, 3747-3764.

Fairall, C. W., E. f. Bradley, J. E. Hare, A. A. Grachev, and J. B. Edson, 2003: Bulk parameterization on air-sea fluxes: Updates and verification for the COARE algorithm. $J$. 
Climate, 16, 571-591.

Freitag, H. P., M. O'Haleck, G.C. Thomas, and M.J. McPhaden, 2001: Calibration procedures and instumental accuracies for ATLAS wind measurements. NOAA. Tech. Memo. OAR PMEL119, NOAA/Pacific Marine Environmental Laboratory, Seattle, Washington, 20 pp.

Freitag, H.P., M.E. McCarty, C. Nosse, R. Lukas, M.J. McPhaden, and M.F. Cronin, 1999: COARE Seacat data: Calibrations and quality control procedures. NOAA Tech. Memo. ERL PMEL115, 89 pp.

Gille, S. T., 2005: Statistical characterization of zonal and meridional ocean wind stress. J. Atmos. Oceanic Technol., 22, 1353-1372

Hackert, E.C., A.J. Busalacchi, and R. Murtugudde, 2001: A wind comparison study using an ocean general circulation model for the 1997-98 El Niño. J. Geophys. Res., 106, 2345-2362.

Han, W., D. M. Lawrence, and P. J. Webster, 2001: Dynamical response of equatorial Indian Ocean to intraseasonal winds: Zonal flow. Geophys. Res. Lett., 28, 4215-4218.

Han, W., G.A. Meehl, B. Rajagopalan, et al., 2010: Patterns of Indian Ocean sea-level change in a warming climate. Nature Geosci., 3, 546-550, DOI: 10.1038/ngeo901.

Han, W., J. P. McCreary, Y. Masumoto, J. Vialard and B. Duncan, 2011 : Basin modes in the equatorial Indian Ocean, J. Phys. Oceanogr., 41, 1252-1270.

Hellerman, S., and M. Rosenstein, 1983: Normal monthly wind stress over the World Ocean with error estimates. J. Phys. Oceanogr., 13,1093-1104.

Huddleston, J. N., and B. W. Stiles, 2000 : Multi dimensional Histogram (MUDH) Rain flag Product Description, Version 2.1. Jet Propulsion Laboratory, Pasadena, CA.

Jayakumar, A., J. Vialard, M. Lengaigne, C. Gnanaseelan, J. P. McCreary, B. Praveen Kumar, 2010: Processes controlling the surface temperature signature of the Madden-Julian Oscillation in the thermocline ridge of the Indian Ocean, Clim. Dyn, online, DOI: 10.1007/s00382-010-0953-5.

Jiang, C., M.F. Cronin, K.A. Kelly, and L. Thompson, 2005: Evaluation of a hybrid satellite- and NWP-based turbulent heat flux product using Tropical Atmosphere-Ocean (TAO) buoys. $J$. Geophys. Res., 110(C9), C09007, doi:10.1029/2004JC002824.

Jiang, C.-L., L. Thompson, K. A. Kelly 2008: Equatorial influence of QuikSCAT winds in an isopycnal ocean model compared to NCEP2 winds, Ocean Modeling, 24, doi: 10.1016/j.ocemod.2008.05.003.

Jiang, C., L. Thompson, K.A. Kelly, and M.F. Cronin 2009: The roles of intraseasonal Kelvin waves and tropical instability waves in SST variability along the equatorial Pacific in an isopycnal ocean model, J. Clim., 22, doi:10.1175/2009JCLI2767.1

Josey S, Kent E Taylor P, 2002: Wind stress forcing of the ocean in the SOC climatology: comparisons with the NCEP-NCAR, ECMWF, UWM/COADS, and Hellerman and Rosenstein datasets. J Phys Oceanogr, 32:1993-2019

Kalnay et al.,1996: The NCEP/NCAR 40-year reanalysis project, Bull. Amer. Meteor. Soc, 77, 437470. 
Kanamitsu, M., W. Ebisuzaki, J. Woolen, J. Potter and M. Fiorino, 2002: NCEP/DOE AMIP-II Reanalysis (R-2). Bull. Amer. Meteor. Soc. 83, 1631-1643.

Kara., A.B., Metzger, E.J. and Bourrassa, M.A, 2007: Ocean current and wave effects on wind stress drag coefficient over the global ocean, Geophys. Res. Lett., 34, L01604, doi: 10.1029/2006GL027849.

Kessler, W.S., M.J. McPhaden, and K.M. Weickmann, 1995: Forcing of intraseasonal Kelvin Waves in the equatorial Pacific. J. Geophys. Res., 100, 10,613-10,631.

Kessler, W.S., Johnson, G.C., Moore, D.W., 2003. Sverdrup and nonlinear dynamics of the pacific equatorial currents. Journal of Physical Oceanography 33, 994-1008.

Kochanski, A., D. Koracin, C. E. Dorman, 2006: Comparison of wind-stress algorithms and their influence on wind-stress curl using buoy measurements over the shelf off Bodega Bay, California, Deep-Sea Research II 53 2865-2886

Lake, B. J., S. M. Norr, H. P. Freitag, and M. J. McPhaden, 2003: Calibration procedures and intrumental accuracy estimates of ATLAS air temperature and relative humidity measurements. NOAA Tech Memo. OAR PMEL-123, NOAA/Pacific Marine Environmental Laboratory, Seattle, WA, 23 pp.

Large, W. G., and S. Pond, 1981: Open ocean momentum flux measurements in moderate to strong winds. J. Phys. Oceanogr., 11, 324-336.

Le Blanc, J-L., and J-P. Boulanger, 2001 : Propagation and reflection of long equatorial waves in the Indian Ocean from TOPEX/POSEIDON data during the 1993-1998 period, Clim. Dyn., 17, 547-557.

Lee, T. and M.J. McPhaden, 2008: Decadal phase change in large-scale sea level and winds in the Indo-Pacific region at the end of the 20th century. Geophys. Res. Lett., 35, L01605, doi:10.1029/2007GL032419.

McCreary, J. P, 1981 : A linear stratified ocean model of the coastal undercurrent. Philosophical Transactions of the Royal Society of London, 298, 603-635.

Lengaigne, M., J.-P. Boulanger, C. Menkes, S. Masson, G. Madec, and P. Delecluse, 2002: Ocean Response to the March 1997 Westerly Wind Event, J. Geophys. Res., 107, 8015, doi:10.1029/2001JC000841, 2002.

Lengaigne, M., J.-P. Boulanger, C. Menkes, G. Madec, P. Delecluse, E. Guilyardi, et J. Slingo, 2003: The March 1997 Westerly Wind Event and the onset of the 1997/98 El Niño: Understanding the role of the atmospheric response. J. Clim., 16, 3330-3343.

Lengaigne, M., J.P. Boulanger, P. Delecluse, C. Menkes et J. Slingo, 2004: Westerly Wind Events and their influence on coupled ocean-atmosphere system: A Review. Earth's Climate: The Ocean-Atmosphere Interaction, Geophys. Monogr., Vol. 147, Amer. Geophys. Union, 49-69.

Lengaigne, M., J.-P. Boulanger, C. Menkes, H. Spencer, 2006: Influence of the seasonal cycle on the termination of El Niño events in a Coupled General Circulation Model, J. Clim., 19, 18501868, doi: 10.1175/JCLI3706.1.

McCreary, J. P., 1981: A linear stratified ocean model of the coastal undercurrent, Philos. Trans. R. Soc, London, 298,603-635. 
McPhaden, M.J., 1999: Genesis and evolution of the 1997-98 El Niño. Science, 283, 950-954.

McPhaden, M. J, 2004: Evolution of the 2002/03 El Niño. Bull. Amer. Meteor. Soc., 85, 677-69

McPhaden, M. J., A. J. Busalacchi, R. Cheney, J. R. Donguy, K. S. Gage, D. Halpern, M. Ji, P. Julian, G. Mayers,, G. T. Mitchum, P. P. Niiler, J. Picaut, R. W. Reynolds, N. Smith, K. Takeuchi, 1998: The Tropical Ocean-Global Atmosphere (TOGA) observing system: A decade of progress. J. Geophys. Res., 103, 14,169-14,240.

McPhaden, M. J., G. Meyers, K. Ando, Y. Masumoto, V. S. N. Murty, M. Ravichandran, F. Syamsudin, J. Vialard, W. Yu, L. Wu, 2009: RAMA: Research Moored Array for AfricanAsian-Australian Monsoon Analysis and Prediction. Bull. Am. Meteor. Soc., 90, 459-480.

McPhaden, M. J., S. E. Zebiak, Sand, M.H. Glantz, 2006: ENSO as an integrating concept in Earth science. Science, 314, 1740-1745.

McPhaden, M.J., K. Ando, B. Bourlès, H.P. Freitag, R. Lumpkin, Y. Masumoto, V.S.N. Murty, P. Nobre, M. Ravichandran, J. Vialard, D. Vousden, and W. Yu, 2010: The global tropical moored buoy array. In Proceedings of the "OceanObs'09: Sustained Ocean Observations and Information for Society" Conference (Vol. 2), Venice, Italy, 21-25 September 2009, Hall, J., D.E. Harrison, and D. Stammer, Eds., ESA Publication WPP-306.

Medavaya, M., D.E. Waliser, R.A. Weller, and M.J. McPhaden, 2002: Assessing ocean buoy shortwave shortwave observations using clear-sky model calculations. J. Geophys. Res., 107(C2), 3014, doi:10.1029/2000JC000558.

Meissner, T., D. Smith, and F. Wentz, 2001: A 10 year intercomparison between collocated Special Sensor Microwave Imager oceanic surface wind speed retrievals and global analyses. $J$. Geophys. Res., 106, 11 731-11 742.

Milliff, R. F.,, J. Morzel, D. Chelton, and M. H. Freilich, 2004: Wind stress curl and wind stress divergence biases from rain effects on QUIKSCAT surface wind retrievals. J. Atmos. Oceanic Technol.,21, 1216-1231.

Nagura, M., and M. J. McPhaden, 2010a: Wyrtki Jet dynamics: Seasonal variability, J. Geophys. Res., 115, C07009, doi:10.1029/2009JC005922.

Nagura, M., and M.J. McPhaden, 2010b: Dynamics of zonal current variations associated with the Indian Ocean dipole, J. Geophys. Res., 115, C11026, doi:10.1029/2010JC006423.

Nagura, M., and M. J. McPhaden, 2012: The dynamics of wind-driven intraseasonal variability in the equatorial Indian Ocean, J. Geophys. Res., 115, C07009, doi:10.1029/2011JC007405.

Nidheesh, A. G., M. Lengaigne, A. S. Unnikrishnan, J. Vialard, 2012: Decadal sea level variability in the tropical Indo-Pacific - results from an ocean model and the CMIP3 databse, Clim. Dyn., in revision.

Oost., W. A., G. J. Komen, C. M. J. Jacobs, and C. Van Oort, 2002: New evidence for a relation between wind stress and wave age from measurements during ASGAMAGE. Bound. Layer Meteor., 103, 409-438.

Payne, R.E., K. Huang, R.A. Weller, H.P. Freitag, M.F. Cronin, M.J. McPhaden, C. Meinig, Y. Kuroda, N. Ushijima, R.M. Reynolds, 2002: A comparison of buoy meteorological systems. WHOI Tech. Rep. WHOI-2002-10. Woods Hole Oceanographic Institution, 67 pp. 
Pegion, P. J., M. A. Bourassa, D. M. Legler, and J. J. O’Brien, 2000: Objectively derived daily "winds" from satellite scatterometer data. Mon. Wea. Rev., 128, 3150-3168.

Plueddemann, A. J., R. A. Weller, R. Lukas, J. Lord, P. R. Bouchard and M. A. Walsh, 2006: WHOI Hawaii Ocean Timeseries Station (WHOTS): WJOTS-2 Mooring Turnaround Cruise Report. WHOI. Tech. Rep. WHOI-2006-08, Woods Hole Oceanographic Institution, 68 pp.

Praveen Kumar, B., J. Vialard, M. Lengaigne, V.S.N. Murty and M.J. McPhaden, 2012: TropFlux: Air-Sea Fluxes for the Global Tropical Oceans - Description and evaluation. Clim. Dyn., 38, 1521-1543, doi: 10.1007/s00382-011-1115-0.

Rienecker, M. M., R. Atlas, S. D. Schubert, and C. S. Willett, 1996: A comparison of surface wind products over North Pacific Ocean. J. Geophys. Res., 101, 1011-1023.

Risien, C. M., and D. B. Chelton, 2008: A Global Climatology of Surface Wind and Wind Stress Fields from Eight Years of QuikSCAT Scatterometer Data. J. Phys. Oceanogr., 38, 23792413.

Rodrigues, R.R., L.M. Rothstein and M. Wimbush, 2007. Seasonal variability of the South Equatorial Current bifurcation in the Atlantic Ocean: A numerical study. J. Phys. Oceanogr. 37, 16-30.

Saji NH, Goswami BN, Vinayachandran PN, Yamagata T, 1999: A dipole mode in the tropical Indian Ocean. Nature, 401, 360-363

Satheesan, K. Sarkar, A. Parekh, A. Kumar, M. R. Kuroda, Y, 2007: Comparison of wind data from QuikSCAT and buoys in the Indian Ocean. International Journal of Remote Sensing. 28; 2375-2382

Schlax, M. G., D. B. Chelton, and M. H. Freilich, 2001: Sampling errors in wind fields constructed from single and tandem scatterometer datasets. J. Atmos. Oceanic Technol., 18, 1014-1036.

Schott, F. A., and J. P. McCreary Jr., 2001: The monsoon circulation of the Indian Ocean. Prog. Oceanogr., 51, 1-123

Sengupta, D., R. Senan, B.N. Goswami and J. Vialard, 2007, Intraseasonal variability of equatorial Indian Ocean zonal currents, J. Clim., 20, 3036-3055.

Serra, Y.L., P.A'Hearn, H.P. Freitag, and M.J. McPhaden, 2001: ATLAS self-siphoning rain gauge error estimates. J. Atmos. Ocean. Technol., 18, 1989-2002.

Smith, S. D., 1988: Coefficients for sea surface wind stress, heat flux and wind profiles as a function ow wind-speed and temperature, J. Geophys. Res., 93, 15467-15472.

Tokinaga, H., and S.-P. Xie, 2011: Wave and Anemometer-based Sea-surface Wind (WASWind) for climate change analysis. J. Climate, 24, 267-285.

Vialard, J., C. Menkes, J.-P. Boulanger, P. Delecluse, E. Guilyardi , M. J. McPhaden, and G. Madec, 2001, Oceanic mechanisms driving the SST during the 1997-1998 El Niño, J. Phys. Oceanogr., 31, 1649-1675.

Vialard. J., A. Jayakumar, C. Gnanaseelan, M. Lengaigne, D. Sengupta, 2012: Processes of intraseasonal sea surface temperature variability in the Northern Indian Ocean during boreal summer. Clim. Dyn., 38, 1901-1916. 
Vialard, J., S.S.C Shenoi, J.P. McCreary, D. Shankar, F. Durand, V. Fernando and S.R. Shetye, 2009: Intraseasonal response of Northern Indian Ocean coastal waveguide to the MaddenJulian Oscillation, Geophys. Res. Lett., 36, L14605, doi:10.1029/2008GL037010.

Wang, C. and Picaut, J. 2004: Understanding ENSO Physics - A Review. In: Earth's climate: the oceanatmosphere interaction. AGU, Washington D.C., C. Wang, S.-P. Xie and J.A. Carton Eds., 21-48.

Webster, P. J., Moore, A. M, Loschnigg, J. P, and Leben, R. R, 1999: Coupled ocean atmosphere dynamics in the Indian Ocean during 1997-98, Nature, 401, 356-360.

Webster, P., and R. Lukas, 1992: TOGA-COARE The Coupled Ocean-Atmosphere Response Experiment. Bull. Amer. Meteor. Soc. 73, 1377-1416.

Weller, R. A., M. F. Baumgartner, S. A. Josey, A. S. Fischer, and J. Kindle, 1998: Atmospheric forcing in the Arabian Sea during 1994-1995: Observations and comparisons with climatology and models, Deep-Sea Res., 45, 1961-1999.

Whelan, S. P., R. A. Weller, R. Lukas, F. Bradley, J. Lord, J. Smith, F. Bahr , P. Lethaby and J. Snyder, 2007: WHOTS-3 Mooring Turnaround Cruise Report. WHOI. Tech. Rep., WHOI2007-03, Woods Hole Oceanographic Institution

Wheeler, M., and Hendon, H. H, 2004: An All-Season Real-time Multivariate MJO index: Development of the index for monitoring and prediction in Australia. Monthly Weather Review, 132, 1917-1932.

Wyrtki, K., 1973: An equatorial jet in the Indian Ocean, Science, 181, 262-264.

Xie, S.-P., and J. A. Carton, 2004: Tropical Atlantic variability: Patterns, mechanisms, and impacts, in Earth's Climate: The Ocean-Atmosphere Interacion, Geophys. Monogr. Ser, vol.147, edited by C. Wang, S.-P. Xie and J. A. Carton, pp.121-142, AGU, Washington, D. C.

Yelland, M., and P. K. Taylor, 1996: Wind stress measurements from the open ocean. J. Phys. Oceanogr, 26, 541-558.

Yu, L., X. Jin, and R. A. Weller, 2007: Annual, Seasonal, and Interannual Variability of Air Sea Heat Fluxes in the Indian Ocean, J. Clim, 20, 3190-3209

Zhang, C., 2005: Madden-Julian Oscillation, Rev. Geophys., 43, RG2003, doi:10.1029/2004RG000158

Zhang, X. and M.J. McPhaden, 2006: Wind stress variations and interannual sea surface temperature anomalies in the eastern equatorial Pacific. J. Clim., 19, 226-241. 


\begin{tabular}{|c|c|c|c|c|}
\hline & Cor & Bias & Std ratio & Rms-error \\
\hline Global (daily) & 0.92 & $0.000 \mathrm{Nm}^{-2}$ & 0.93 & $0.013 \mathrm{Nm}^{-2}$ \\
\hline Global (5-day) & 0.95 & $0.003 \mathrm{Nm}^{-2}$ & 0.95 & $0.009 \mathrm{Nm}^{-2}$ \\
\hline Indian Ocean & 0.97 & $0.001 \mathrm{Nm}^{-2}$ & 0.98 & $0.008 \mathrm{Nm}^{-2}$ \\
\hline Pacific Ocean & 0.94 & $0.005 \mathrm{Nm}^{-2}$ & 0.94 & $0.010 \mathrm{Nm}^{-2}$ \\
\hline Atlantic Ocean & 0.95 & $0.003 \mathrm{Nm}^{-2}$ & 0.95 & $0.010 \mathrm{Nm}^{-2}$ \\
\hline
\end{tabular}

Table 1: Evaluation statistics of TropFlux wind stress magnitude against high-quality TPR mooring observations over the QuikSCAT period. The first rows of values are statistics for daily data; the rest are for 5-day smoothed data. Statistical quantities are correlation, TropFlux minus TPR bias, standard deviation of TropFlux divided by standard deviation of TPR, and root-mean-square error of TropFlux to the TPR. In order to obtain estimates of the percentage of accuracy of pentad Tropflux wind stress estimates, the rms-error should be divided by the average root-mean-square value of TPR wind stress magnitude of $0.061 \mathrm{Nm}^{-2}$ (the value for TropFlux is very close). 
(a) Stress evaluation sites
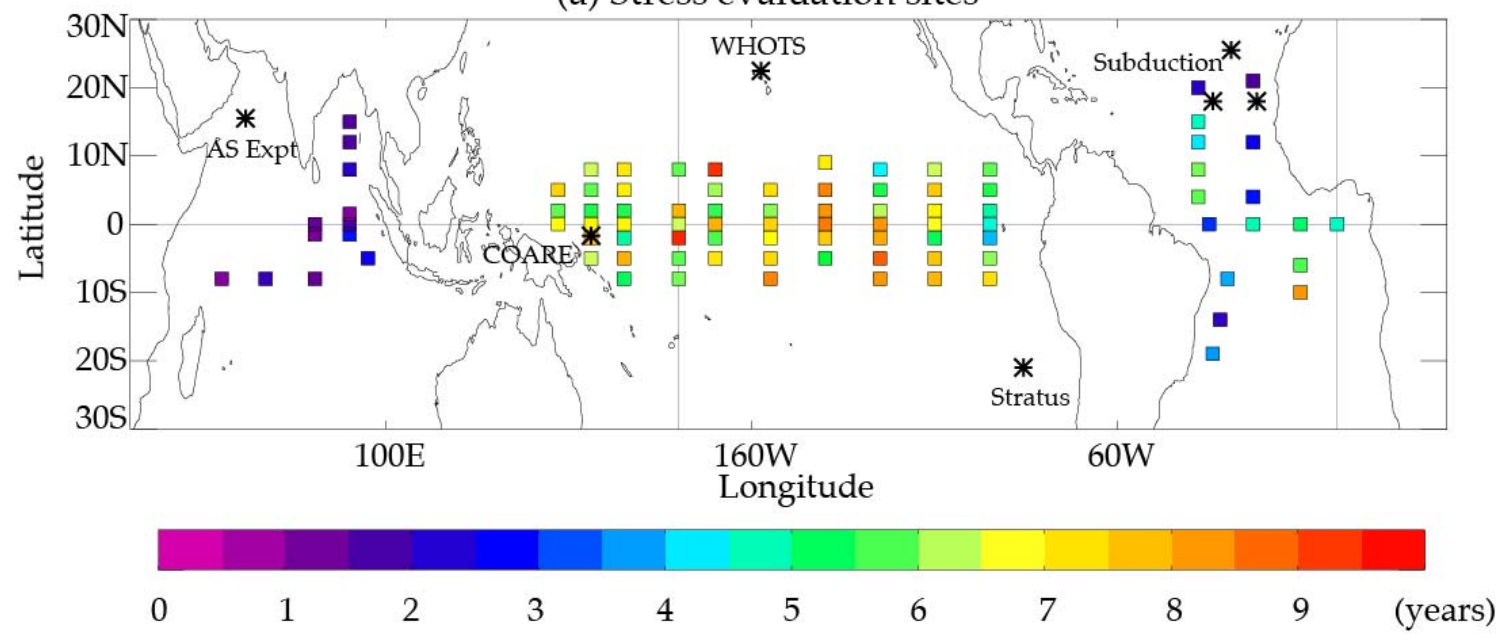

(b) Number of valid observations for wind stress evaluation

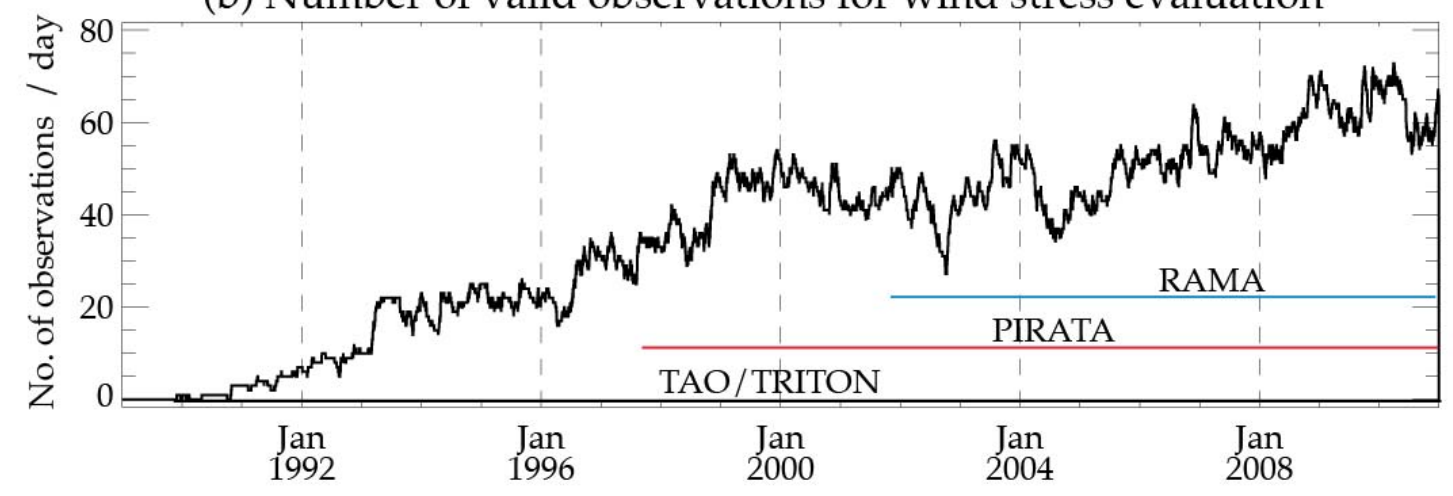

Figure 1: (a) Total length of valid (quality flag 1 or 2) wind stress estimates, in years, over the QuikSCAT period ( $1^{\text {st }}$ August 1999 to $31^{\text {st }}$ July 2009) at TPR (TAO-TRITON/PIRATA/RAMA) sites. Only mooring locations with more than 180 days of high quality data are shown here. Black asterisks indicate locations of independent OceanSITES validations sites. (b) Total number of high quality wind stress estimates available from the TPR array per day. The black, red and blue lines in bottom panel represent the period over which data are available from TAO/TRITON, PIRATA and RAMA respectively. 

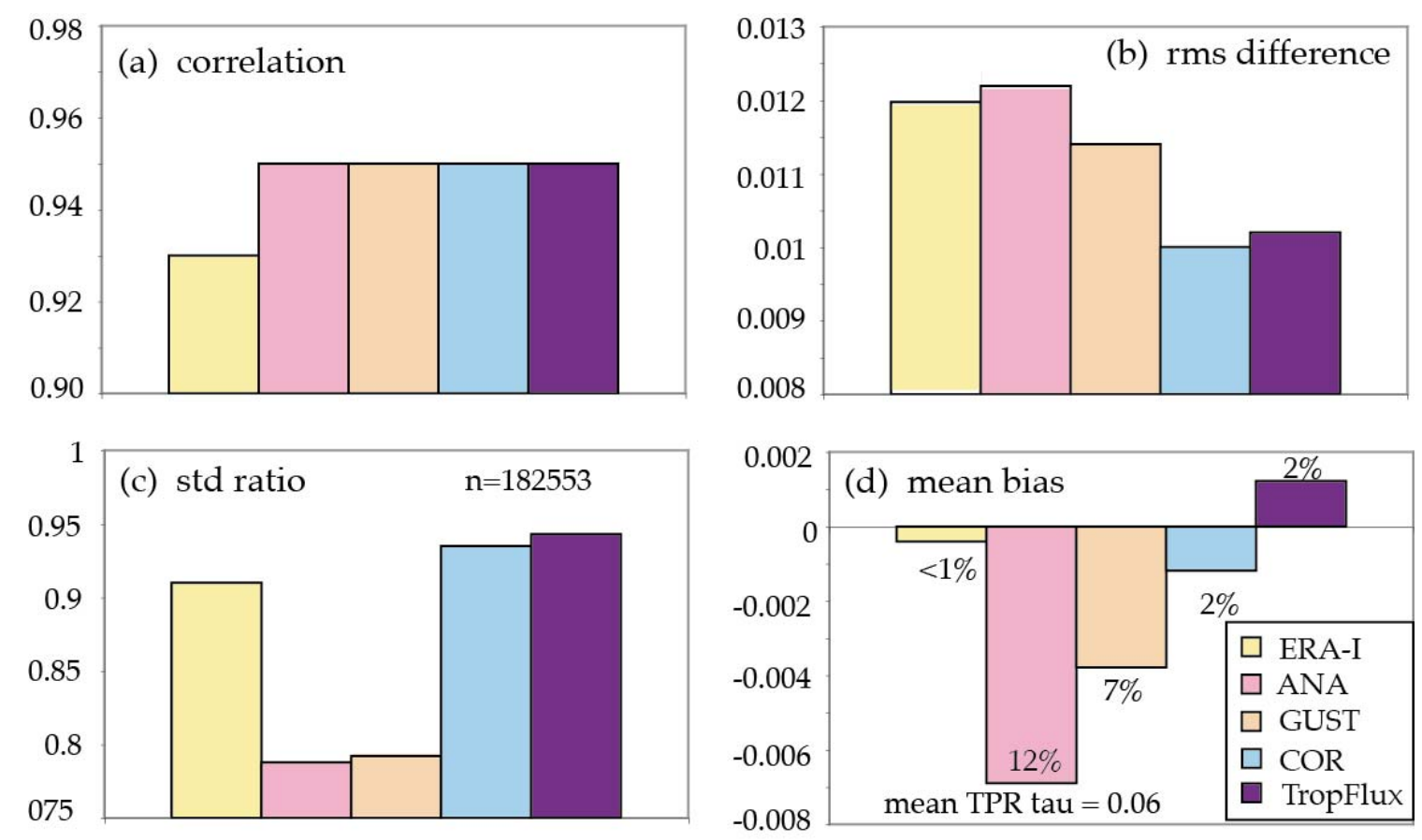

Figure 2: Bar diagrams showing evaluation of 5-day average wind stress magnitude from different products to those computed from TPR (TAO-PIRATA-RAMA) moored buoy arrays. Statistics are computed at each site with more than 180 days of high quality data over QuikSCAT period and then averaged over the whole TPR array. Statistics from ERA-I stresses are shown in yellow. The other colors indicate the various steps in the TropFlux wind stresses computation: (see text for details). The stresses recomputed from analyzed ERA-I parameters (ANA) are shown in pink. Stresses recomputed with a gustiness correction (GUST) are shown in salmon. Stresses recomputed with a bias and amplitude correction (COR) are shown in light blue. TropFlux is shown in purple. The percentages in panel $\mathbf{d}$ correspond to percentage of deviation from the mean TPR value $\left(0.06 \mathrm{Nm}^{-2}\right)$. These statistics are computed against 182553 high quality daily TPR observations. 
(a) correlation

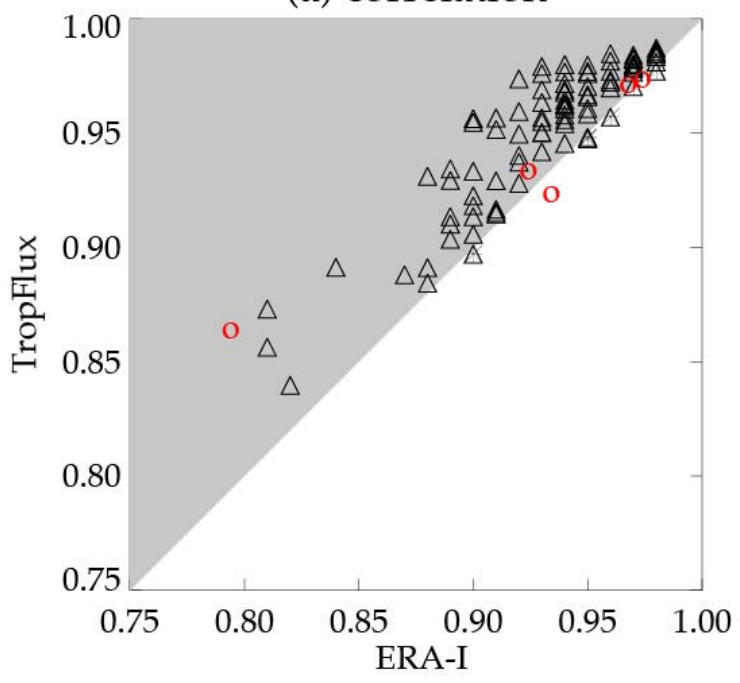

(c) std ratio

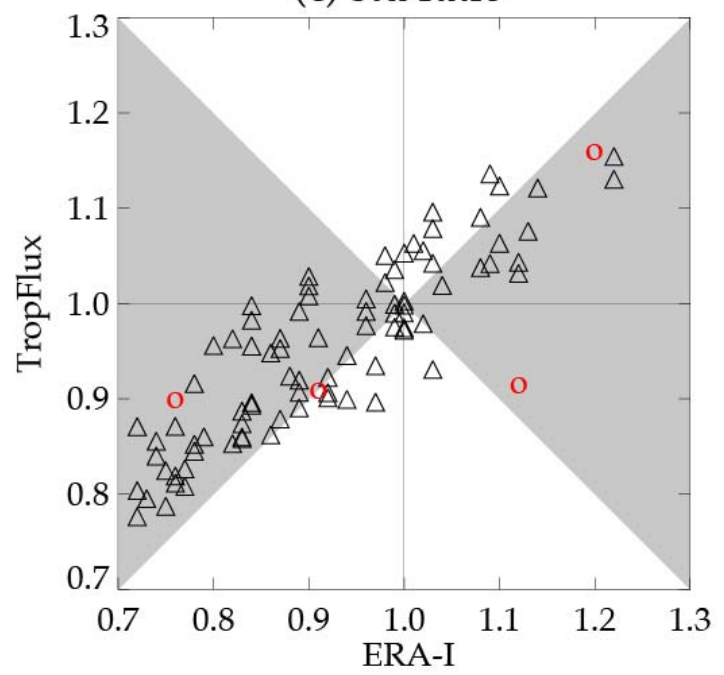

(b) mean bias

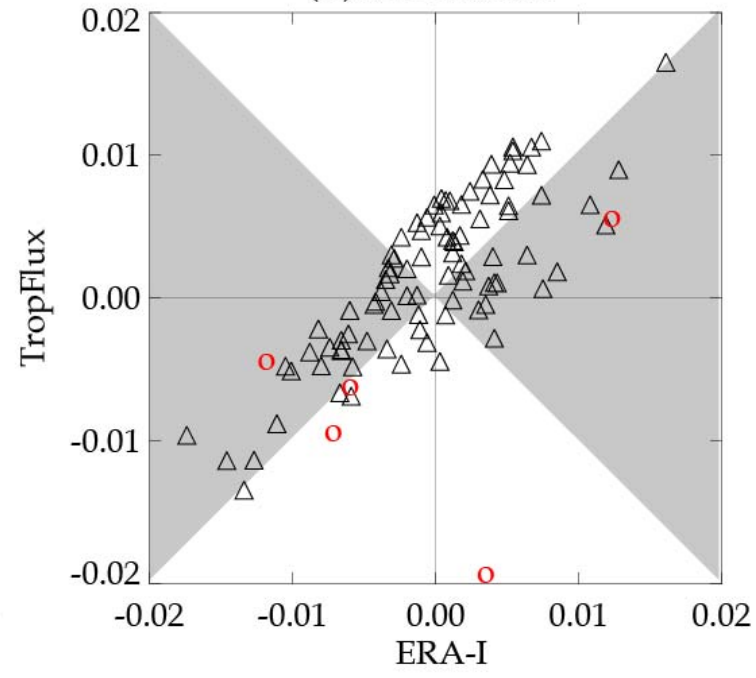

(d) rms difference

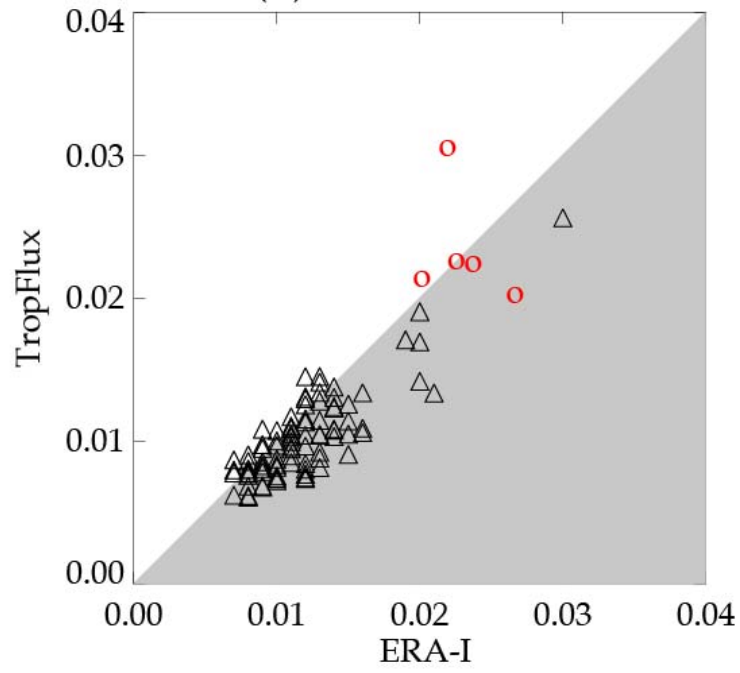

Figure 3: Scatterplot of evaluation statistics (over the QuikSCAT period) of TropFlux (y-axis) against ERA-I (x-axis) to TPR (black diamonds show statistics at each site) and OceanSITES (red circles show statistics at each site) mooring data. The panel a shows correlation, $\mathbf{b}$ shows mean bias at each mooring site, $\mathbf{c}$ shows the standard deviation ratio and $\mathbf{d}$ the root mean square difference. The grey shading on the plot delineates the sites where TropFlux is improved with respect to ERA-I for a given statistic. 

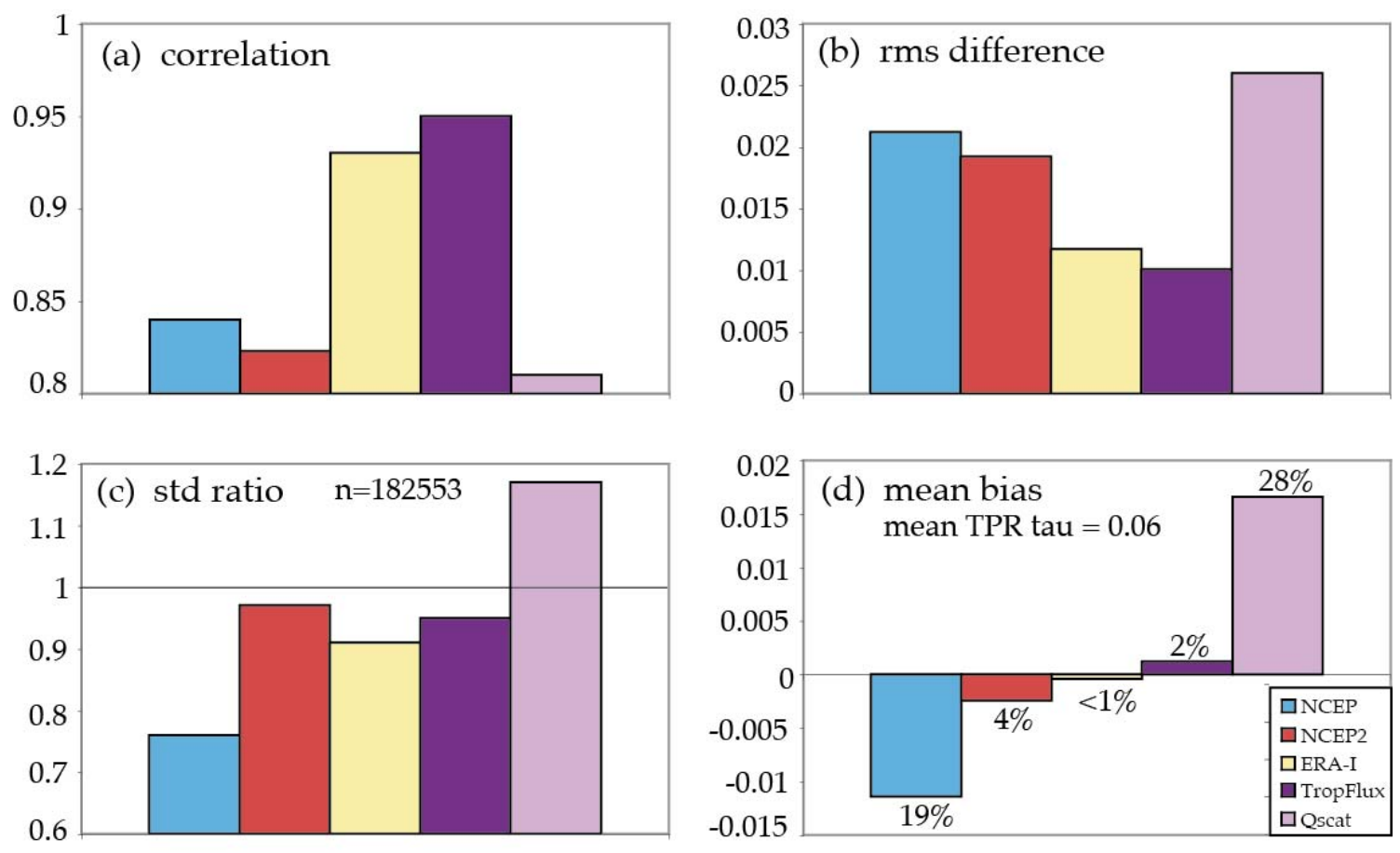

Figure 4: Bar diagrams showing evaluation of 5-day average wind stress magnitude from different products to those computed from TPR (TAO-PIRATA-RAMA) moored buoy arrays. Statistics are computed at each site with more than 180 days of high quality data over QuikSCAT period and then averaged over the whole TPR array. NCEP is shown in blue, NCEP2 in red, ERA-I in yellow, TropFlux in purple, and QuikSCAT in light purple. The percentages in panel $\mathbf{d}$ correspond to percent of deviation from the mean TPR value $\left(0.06 \mathrm{Nm}^{-2}\right)$. These statistics are computed against 182553 high quality daily TPR observations. 
a) TAUX Correlation (TropFlux, Qscat)

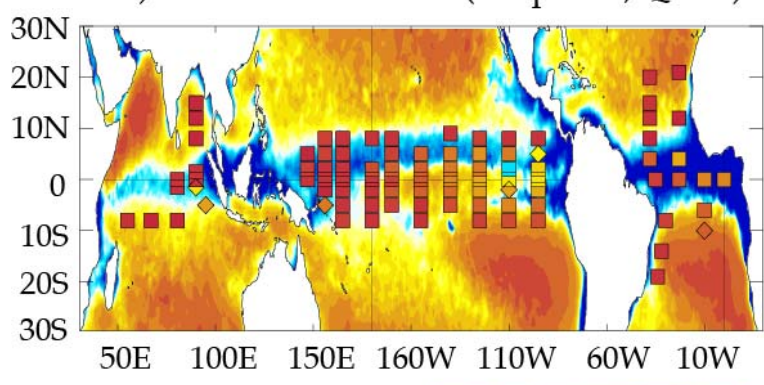

b) TAUY Correlation (TropFlux, Qscat)

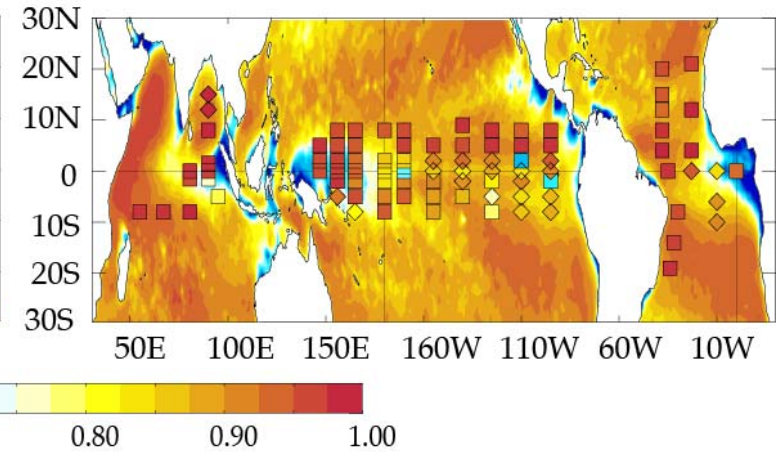

c) TAUY RMSD (TropFlux, Qscat)

c) TAUX RMSD (TropFlux, Qscat)

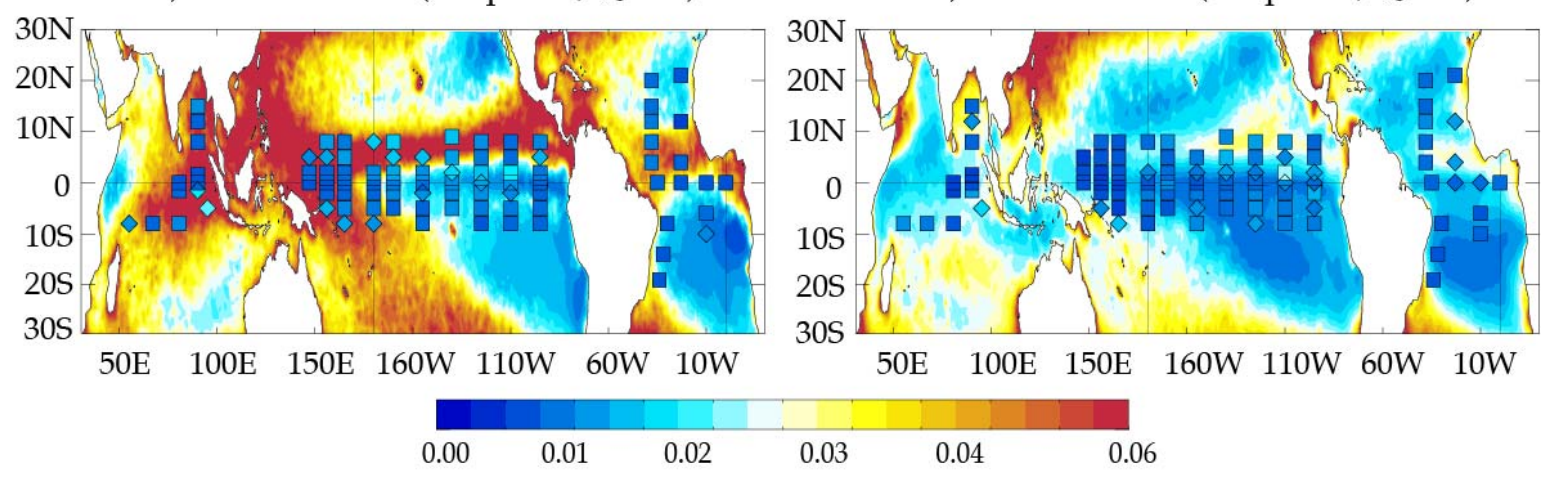

Figure 5: Maps of correlation (a, b) and root mean square differences (c, d) between TropFlux and QuikSCAT zonal (a, c) and meridional (b, d) wind stresses. The statistics are computed over the whole QuikSCAT period. The statistics of the comparison to TPR mooring is plotted with the same color code with a symbol at each site. A square is used to indicate TPR site whenever the evaluation statistic of the TropFlux product is the best (i.e. highest correlation, lowest rms-difference) among NCEP, NCEP2, ERA-I and QuikSCAT; a diamond is used otherwise. TropFlux displays the highest correlation to TPR data for zonal wind stress at 84 sites out of 90 locations (66 out of 90 for meridional wind stress). It has the lowest rms-difference at 73 sites for zonal wind stress (71 for meridional wind stress). 

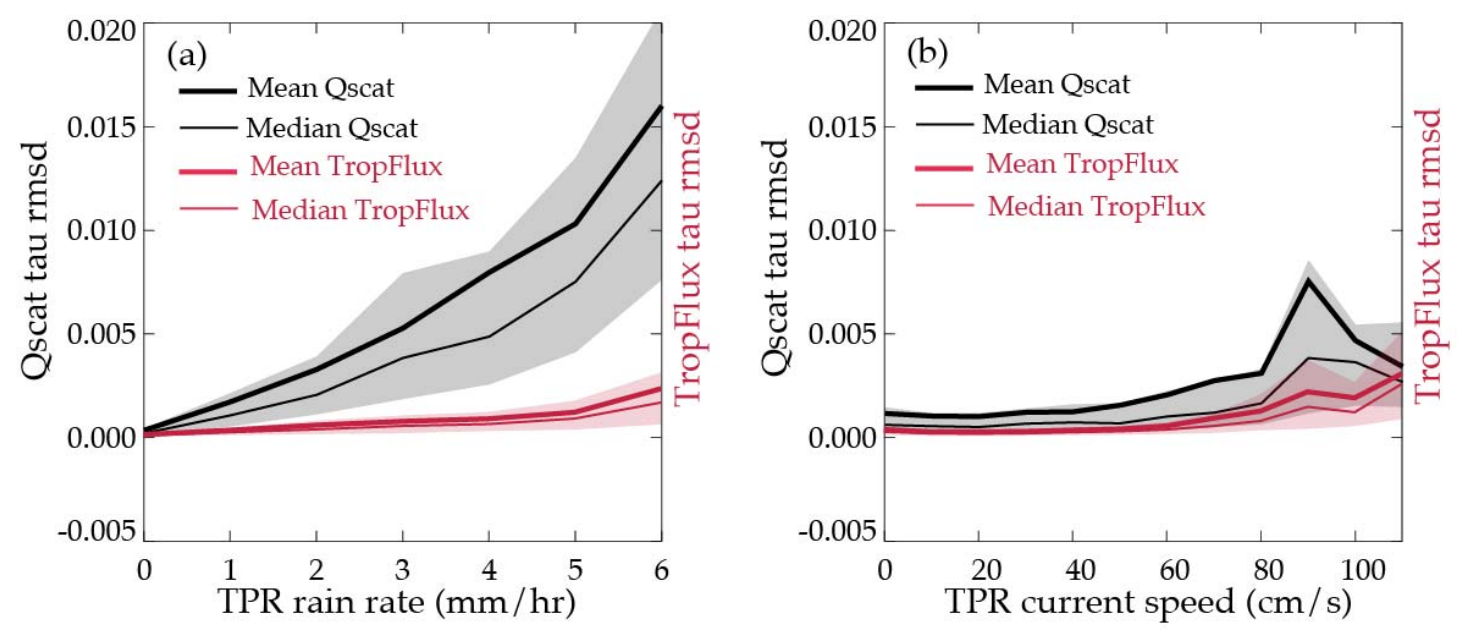

Figure 6: Average (thick curves) and median (thin curves) root mean square difference between QuikSCAT (black / grey) and TropFlux (red) and TPR mooring wind stresses, as a function of TPR (a) rain rates and (b) current speed. The shading delineates the $1^{\text {st }}$ and $3^{\text {rd }}$ quartiles of the root-meansquare difference. In order to obtain these statistics, the QuikSCAT and TropFlux differences with TPR wind stress data have been binned depending on the TPR-measured value of the rain rate (a) or current speed (b), when both were available. The bin size was taken as 1/2 of the overall standard deviation of rain (a) and currents (b). The TPR wind stress estimates used in this plot account for the effect of surface current on wind stress. 

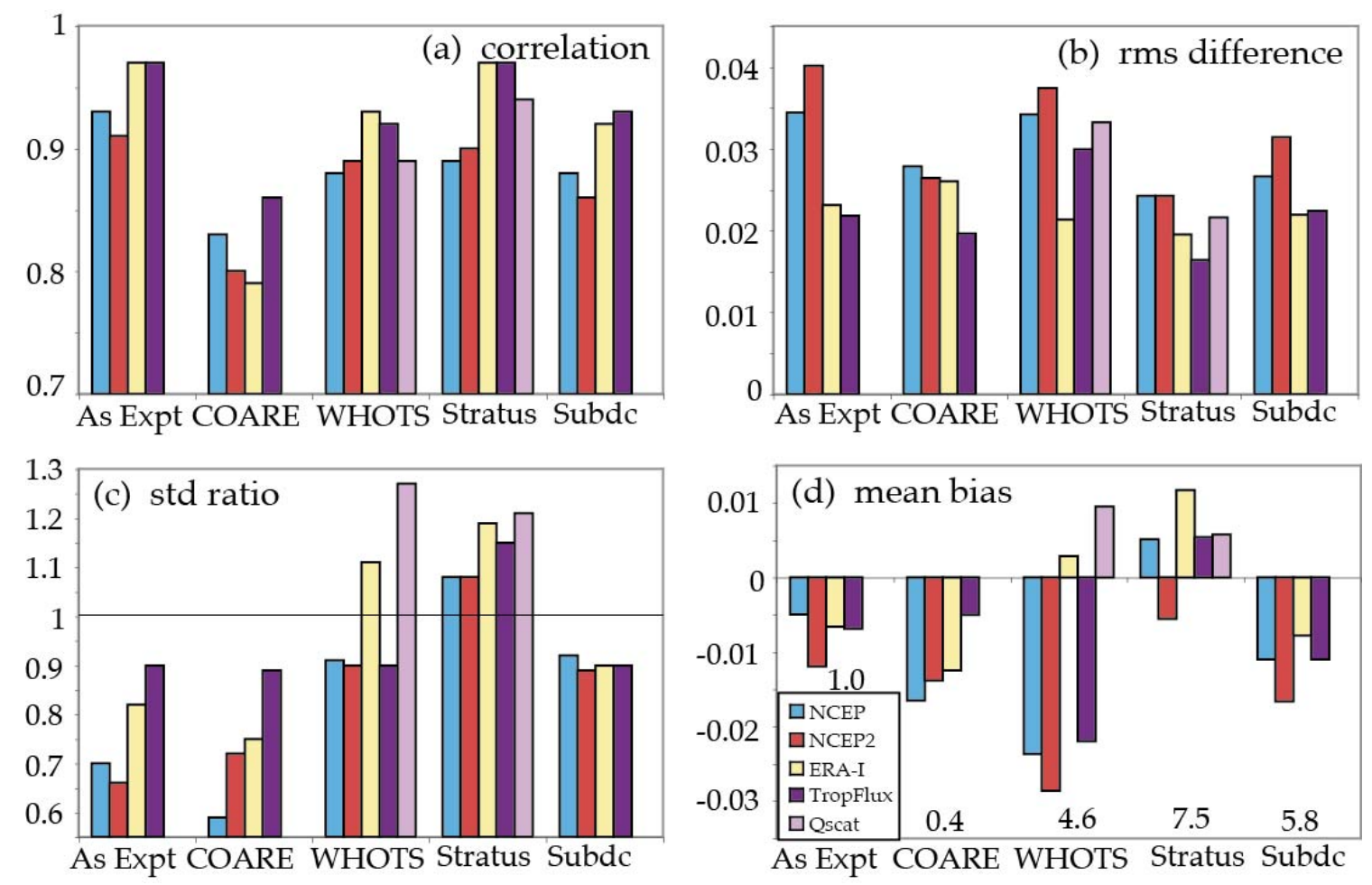

Fig 7. Bar diagrams showing validation of daily wind stresses from different sources against independent data from five moorings. Blue color denotes NCEP, red denotes NCEP2, yellow denotes ERA-I, purple denotes TropFlux and violet denotes QuikSCAT. The length of available data at each location is described in the text. The numbers at the bottom of panel $\mathbf{d}$ represents the number of observations used (in years) for the validation. Note that we have averaged the statistics from the three locations at the Subduction site. 
(a) climatological Wind stress - TropFlux $0.20 \longrightarrow$
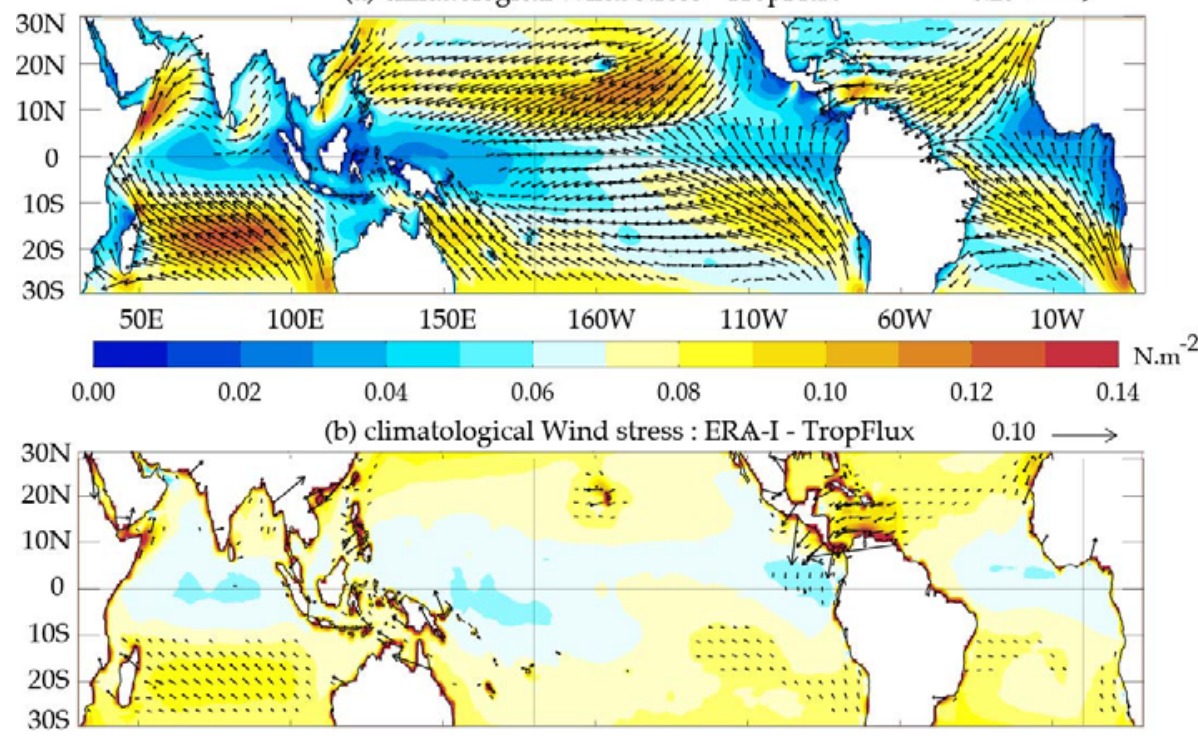

(c) climatological Wind stress: Qscat - TropFlux

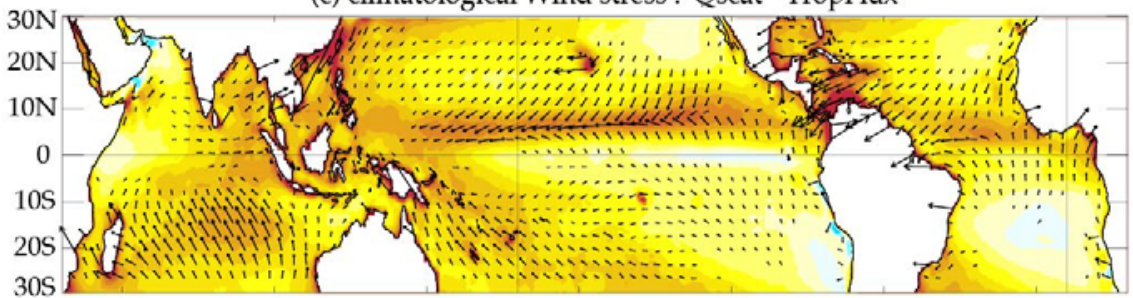

(d) climatological Wind stress : NCEP - TropFlux

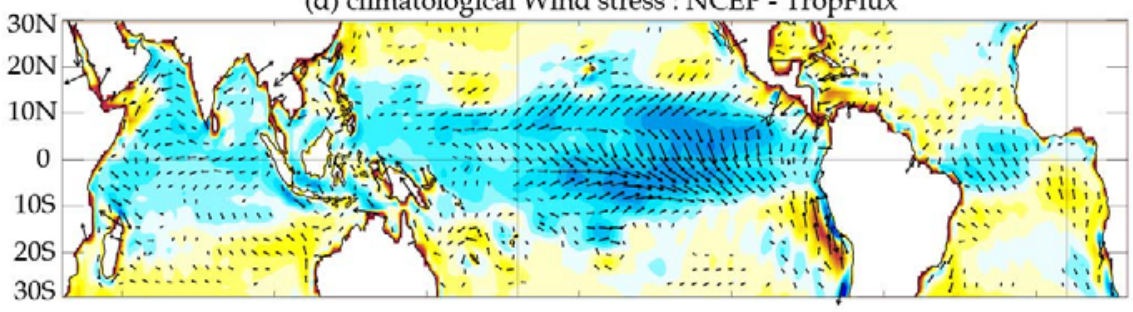

(e) climatological Wind stress : NCEP2 - TropFlux

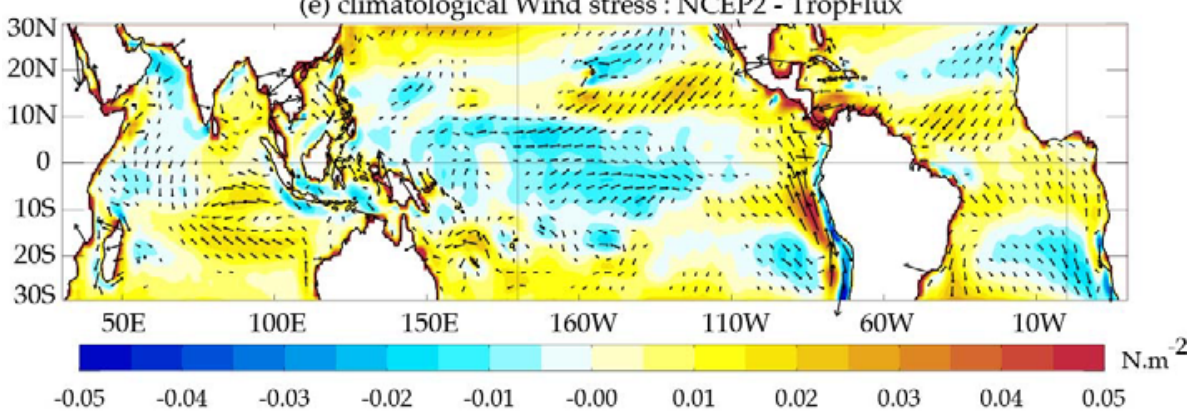

Figure 8 (a) Long term (2000-2008) annual mean wind stress vectors (arrows) and magnitude (shading) from TropFlux. Differences between the long term mean wind stress magnitudes from (b) ERA-I, c) the QuikSCAT, d) NCEP, e) NCEP2 and TropFlux 


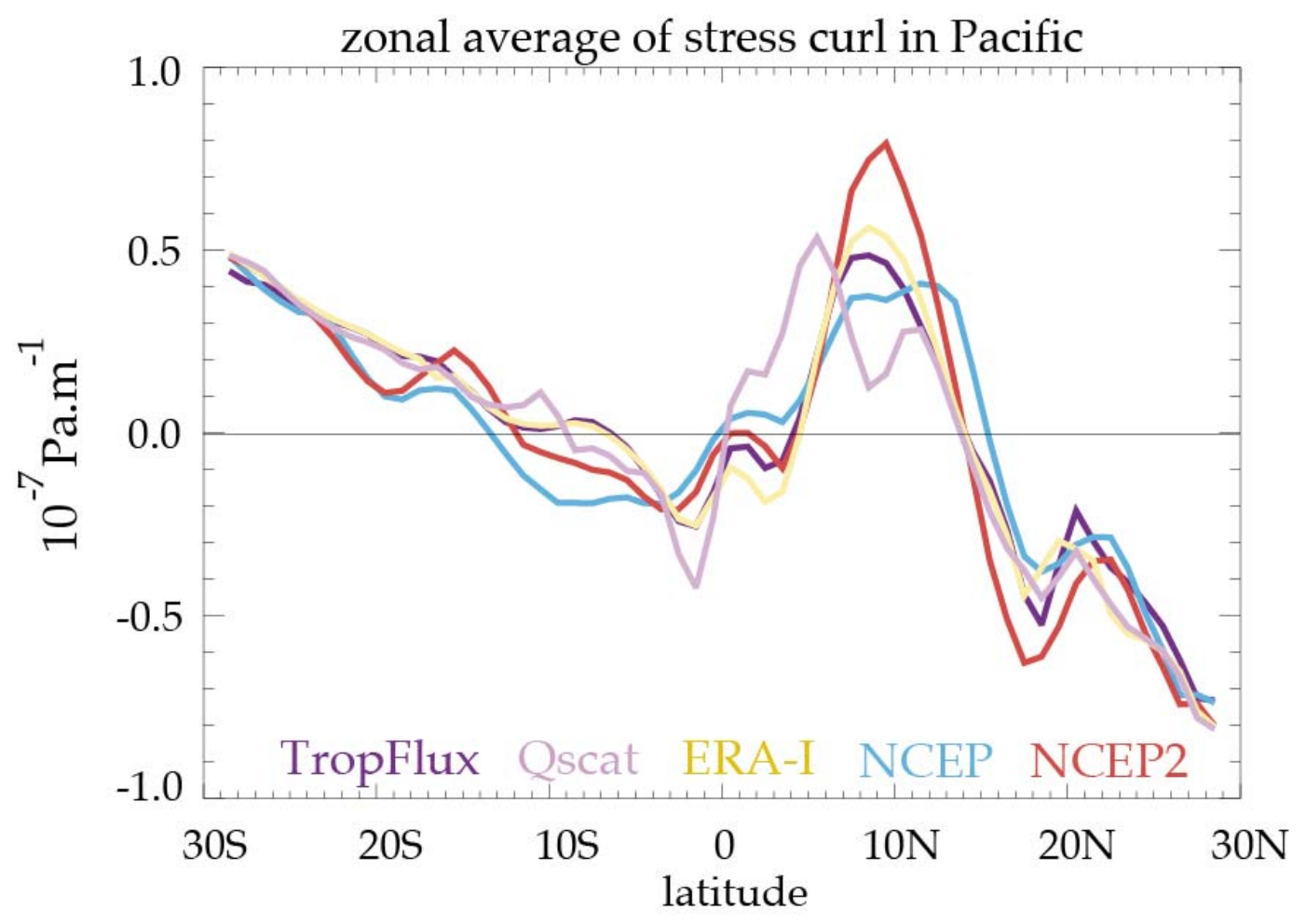

Figure 9: Zonal average of wind stress curl in tropical Pacific (averaged between the dateline and $100^{\circ} \mathrm{W}$ ) from different sources over 2000-2008. 
(a) mean zonal wind stress along the equator over the Qscat period

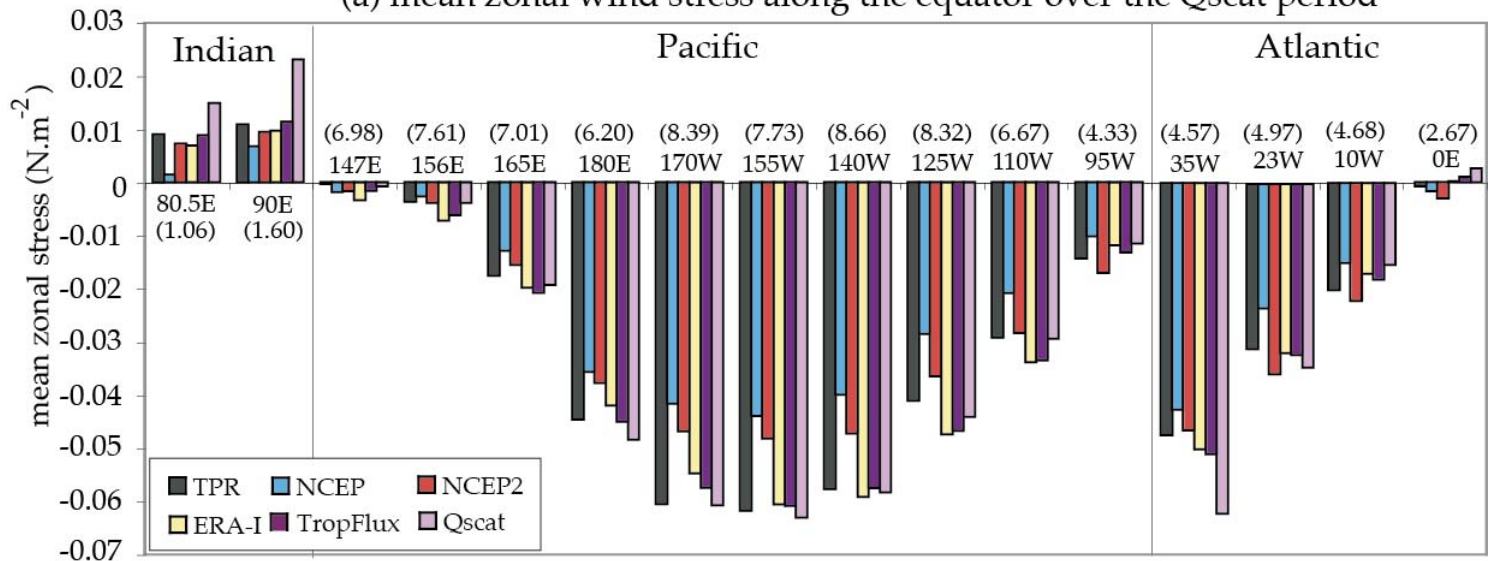

(b) mean zonal wind stress bias along the equator over the Qscat period

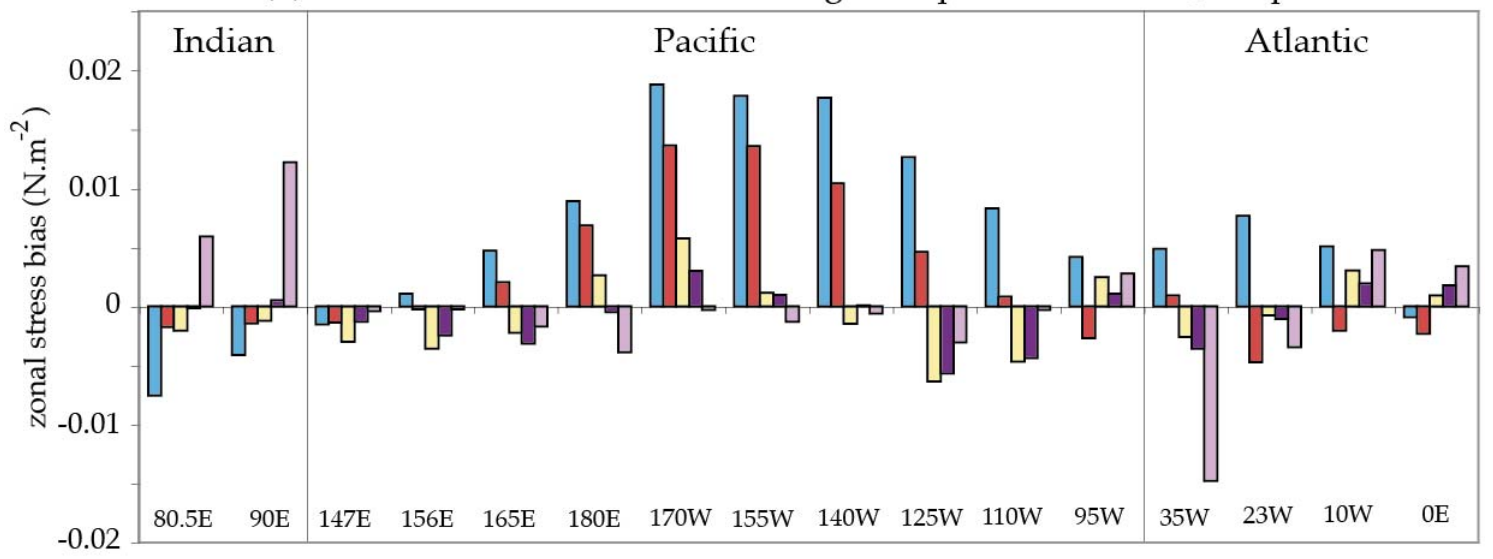

Figure 10: (a) Bar diagrams of comparison between long-term mean zonal wind stress values from the TPR array with other products along the equator over the QuikSCAT period. The locations are mentioned in the figure and numbers in brackets correspond to the total number of available observations over the QuikSCAT period for evaluation (in years). (b) The mean zonal stress bias (product-TPR values) along the equator. TPR locations with a minimum of 365 valid observations over the QuikSCAT period are used to calculate the mean values. 
(a) intraseasonal (10-90 day) taux correlation

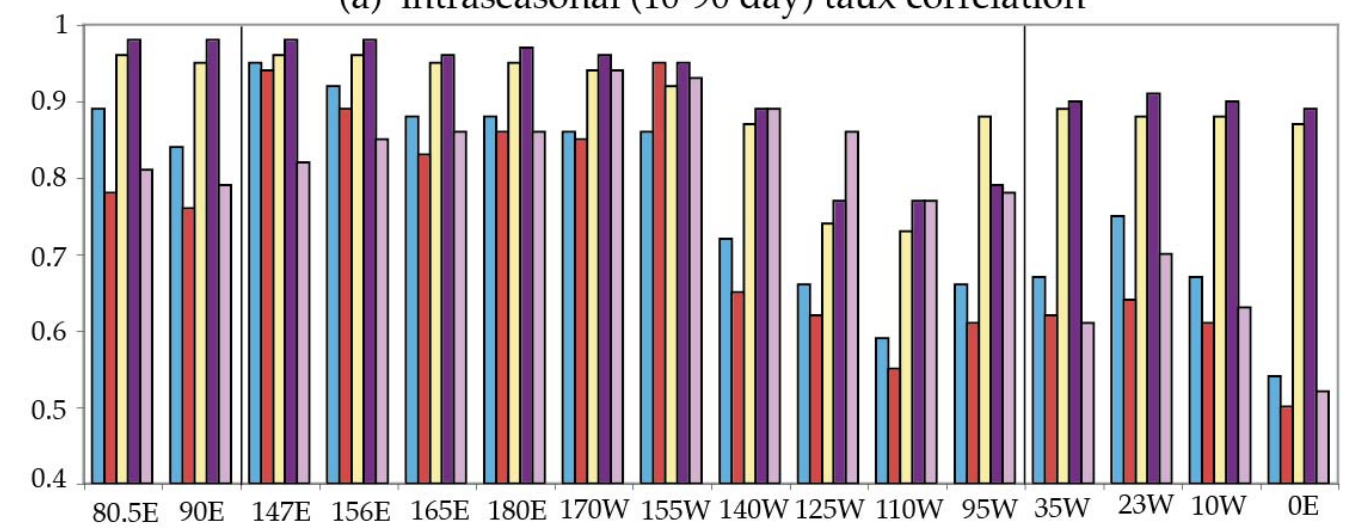

(b) intraseasonal (10-90day) taux standard deviation and its ratio

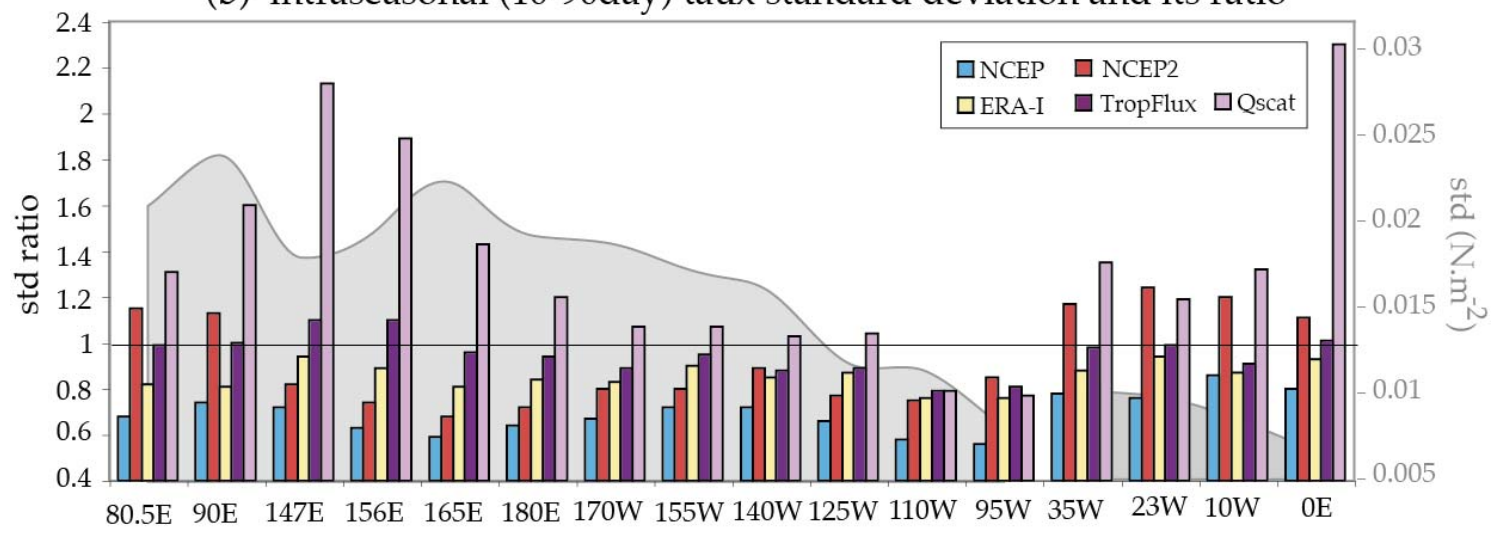

Figure 11. Bar diagrams showing (a) correlation and (b) standard deviation ratio of intraseasonal (10-90 days filtered) zonal wind stress from various products compared to the TPR observations along the equator. In panel $\mathbf{b}$, the observed 10-90 day standard deviation from TPR data is shown as a grey shading in the background (scale on the right of the plot). Different products are shown in different colors. Statistics are calculated over all the available valid data from TPR array over 19902010 period except for QuikSCAT. For QuikSCAT statistics are calculated over the entire QuikSCAT period. Note that similar results are obtained for other products when statistics are calculated over QuikSCAT period. 
(a) intraseasonal (10-90 days) taux at $0^{\circ} \mathrm{N} 156^{\circ} \mathrm{E}$

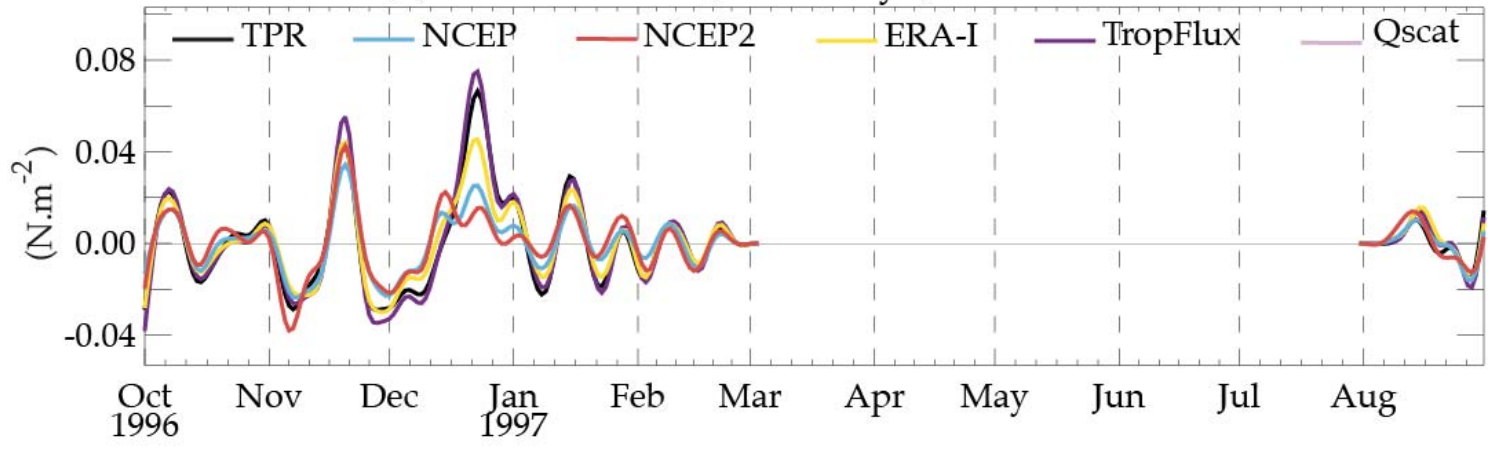

(b) intraseasonal (10-90 days) taux at $0^{\circ} \mathrm{N} 165^{\circ} \mathrm{E}$

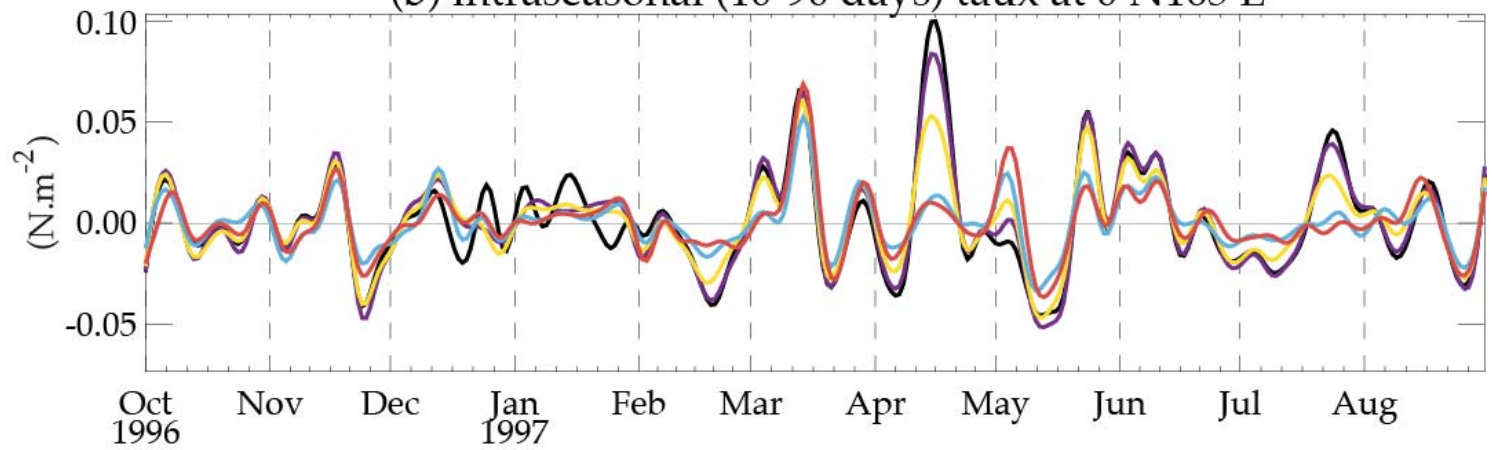

Figure 12: Intraseasonally filtered (10-90 days) zonal wind stress from different products at (a) $0^{\circ} \mathrm{N} 156^{\circ} \mathrm{E}$ and (b) $0^{\circ} \mathrm{N} 165^{\circ} \mathrm{E}$. The mooring timeseries is shown in black, TropFlux in purple, ERA-I in yellow, QuikSCAT in violet, NCEP in blue and NCEP2 in red. 


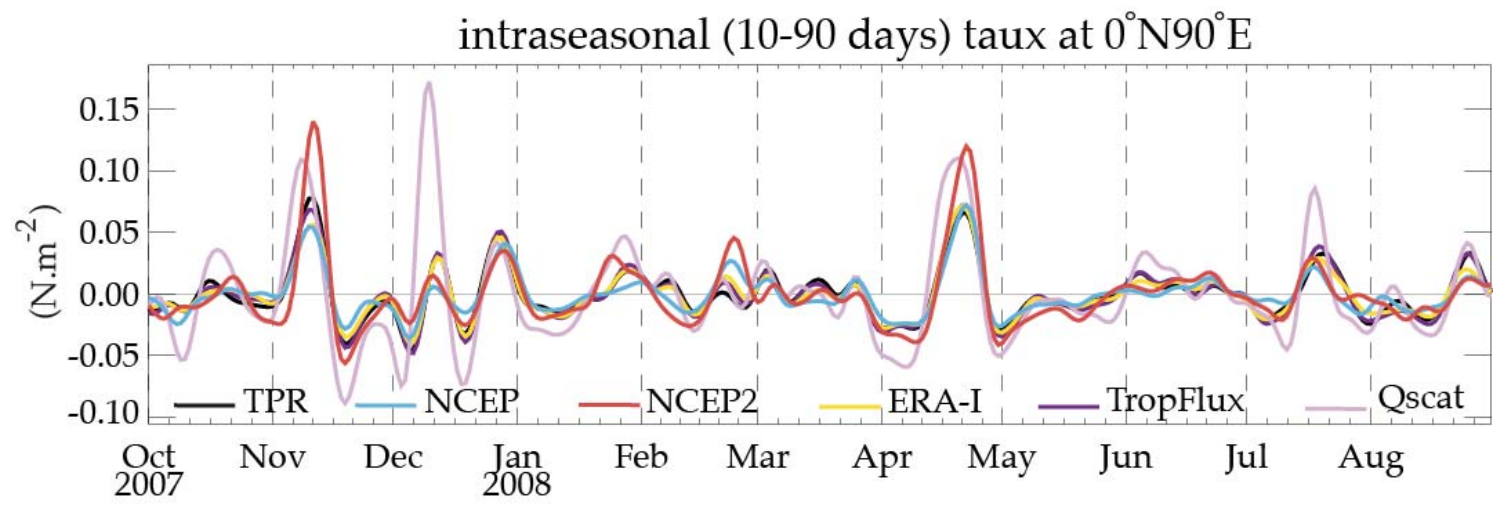

Figure 13: Intraseasonally filtered (10-90 days) zonal wind stress from different products at $0^{\circ} \mathrm{N} 90^{\circ} \mathrm{E}$. The mooring timeseries is shown in black, TropFlux in purple, ERA-I in yellow, QuikSCAT in violet, NCEP in blue and NCEP2 in red. 
(a) mean seasonal cycle taux correlation
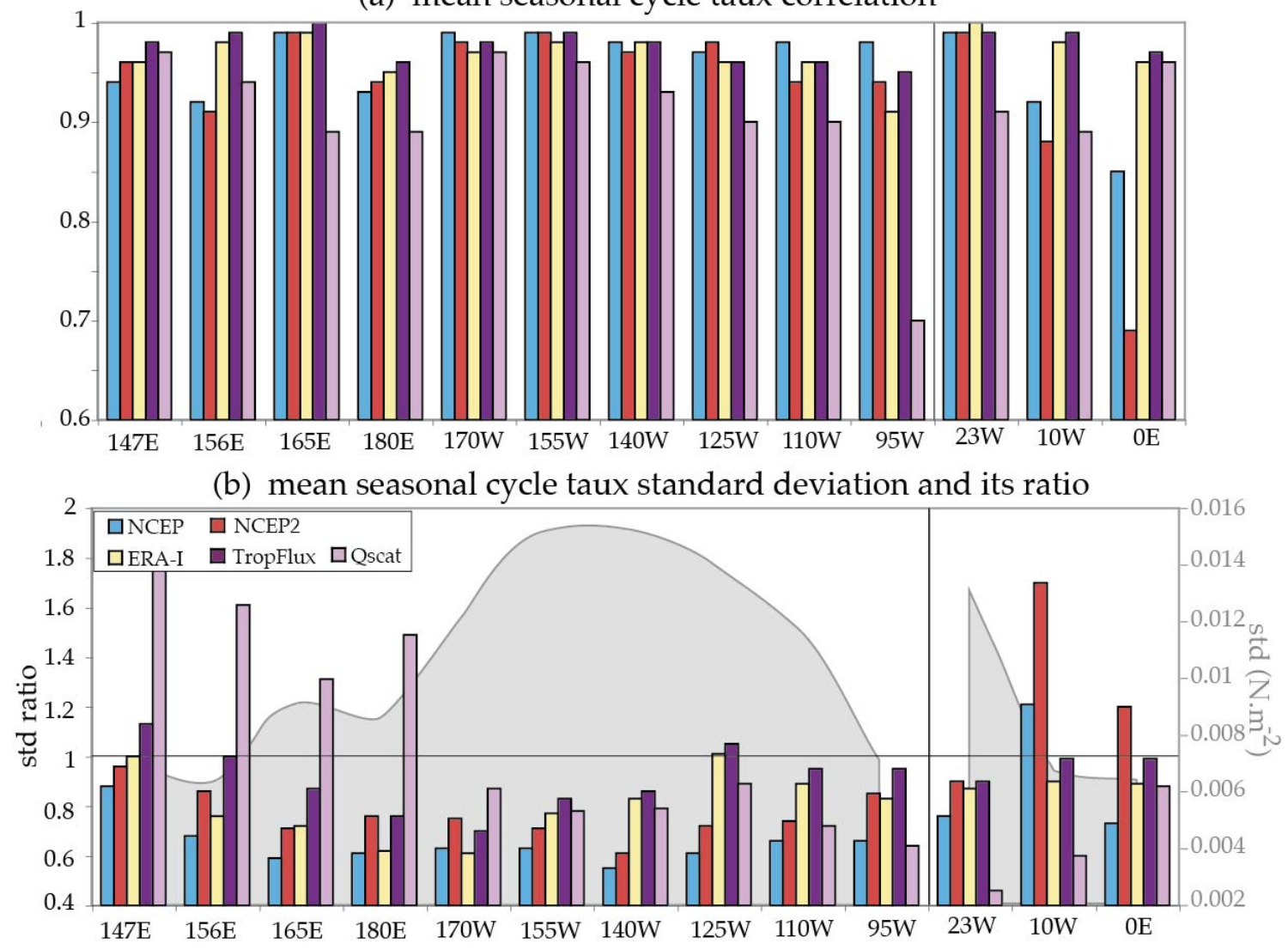

Figure 14. Bar diagrams showing (a) correlation and (b) standard deviation ratio of the long-term mean seasonal cycle zonal wind stress from various products compared to the TPR observations along the equator. In panel $\mathbf{b}$, standard deviation of the observed seasonal cycle from TPR data is shown as a grey shading in the background (scale on the right of the plot). Different products are shown in different colors. Statistics are calculated over all the available valid data from TPR array over 1990-2010 period except for QuikSCAT. Locations with a minimum of 4 years of TPR data are used for this analysis. For QuikSCAT, statistics are calculated over the entire QuikSCAT period. Note that similar results are obtained for other products when statistics are calculated over QuikSCAT period. 
(a) interannual taux correlation

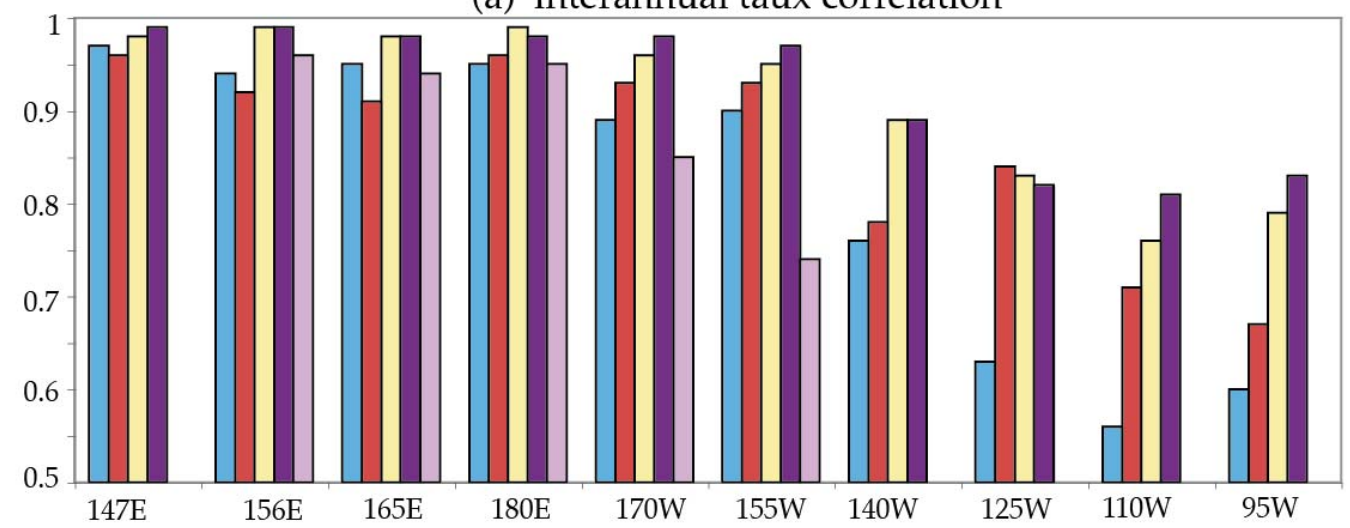

(b) interannual taux standard deviation

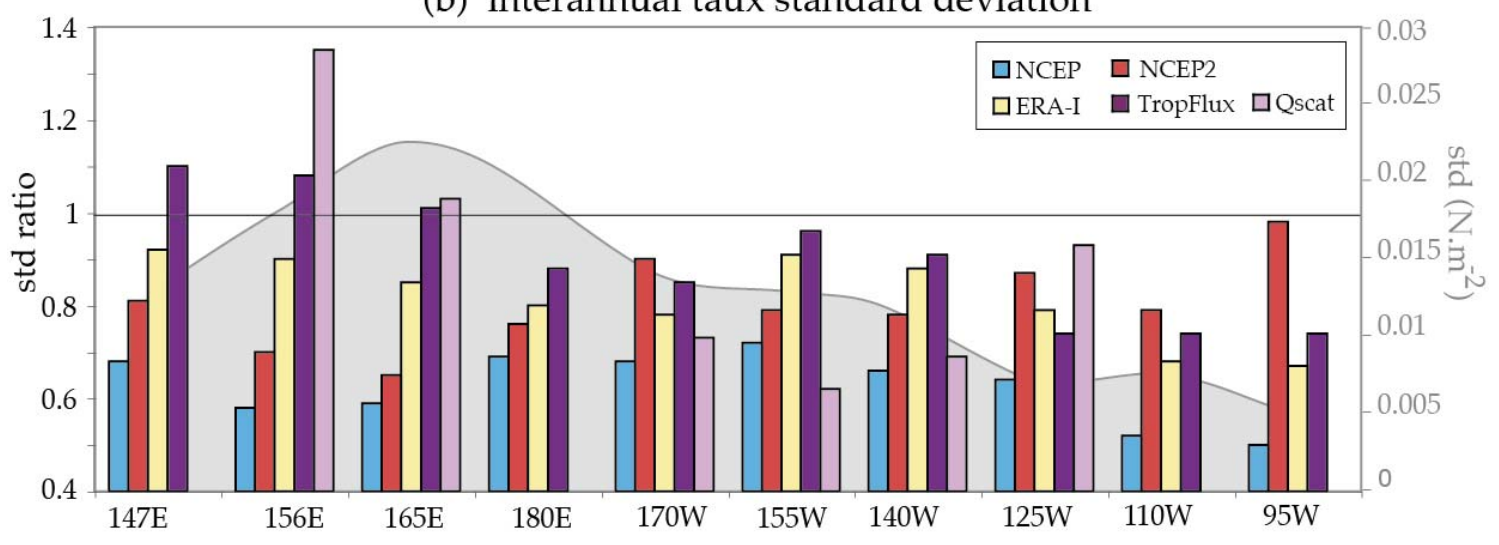

Figure 15. Bar diagrams showing (a) correlation and (b) standard deviation ratio of interannual zonal wind stress from various products compared to the TPR observations along the equator. In panel b, standard deviation of the observed interannual stresses from TPR data is shown as a grey shading in the background (scale on the right of the plot). Different products are shown in different colors. Statistics are calculated over all the available valid data from TPR array over 1990-2010 period except for QuikSCAT. Locations with a minimum of 7 years of high quality TPR data are used for this statistics. For QuikSCAT statistics are calculated over the entire QuikSCAT period. Note that similar results are obtained for other products when statistics are calculated over QuikSCAT period. 
a) normalized spread of tau among NCEP, NCEP2, ERA-I, TropFlux, Qscat

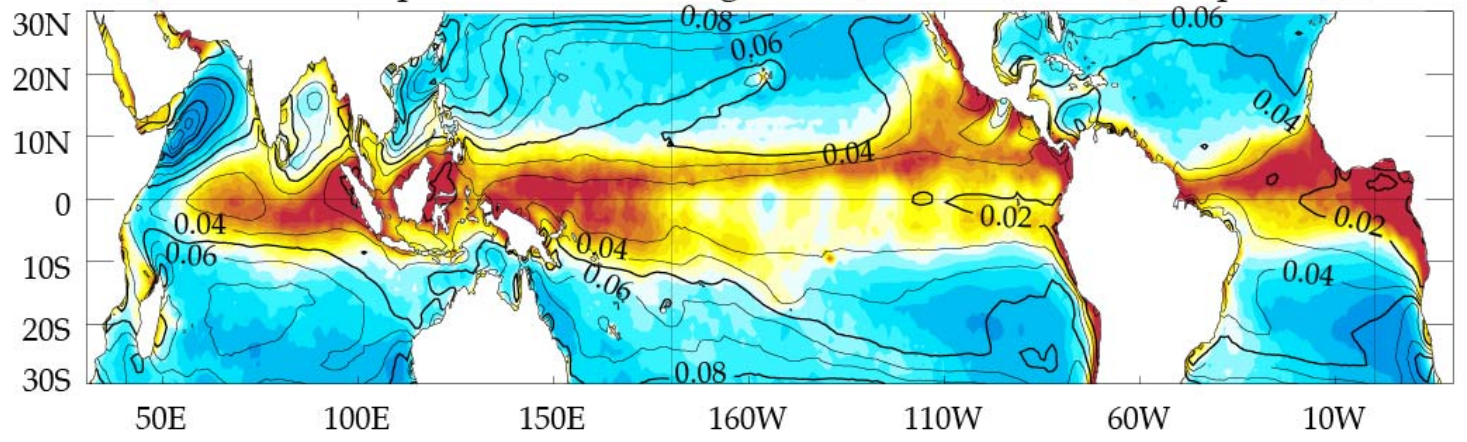

(b) normalized spread of tau among NCEP, NCEP2, ERA-I, TropFlux

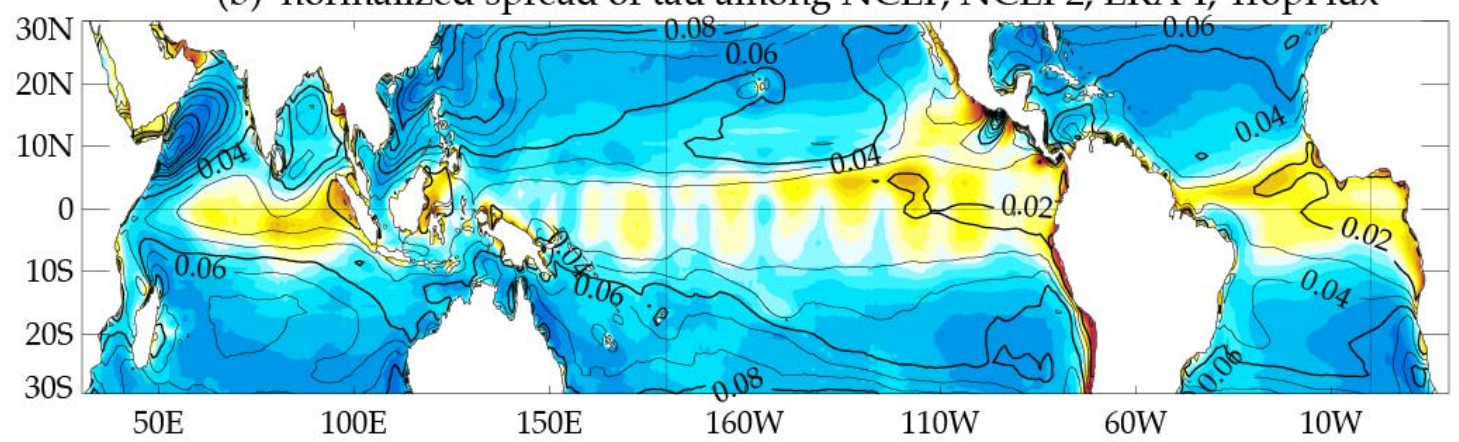

c) normalized spread of net flux among NCEP, NCEP2, ERA-I, TropFlux, OAFlux

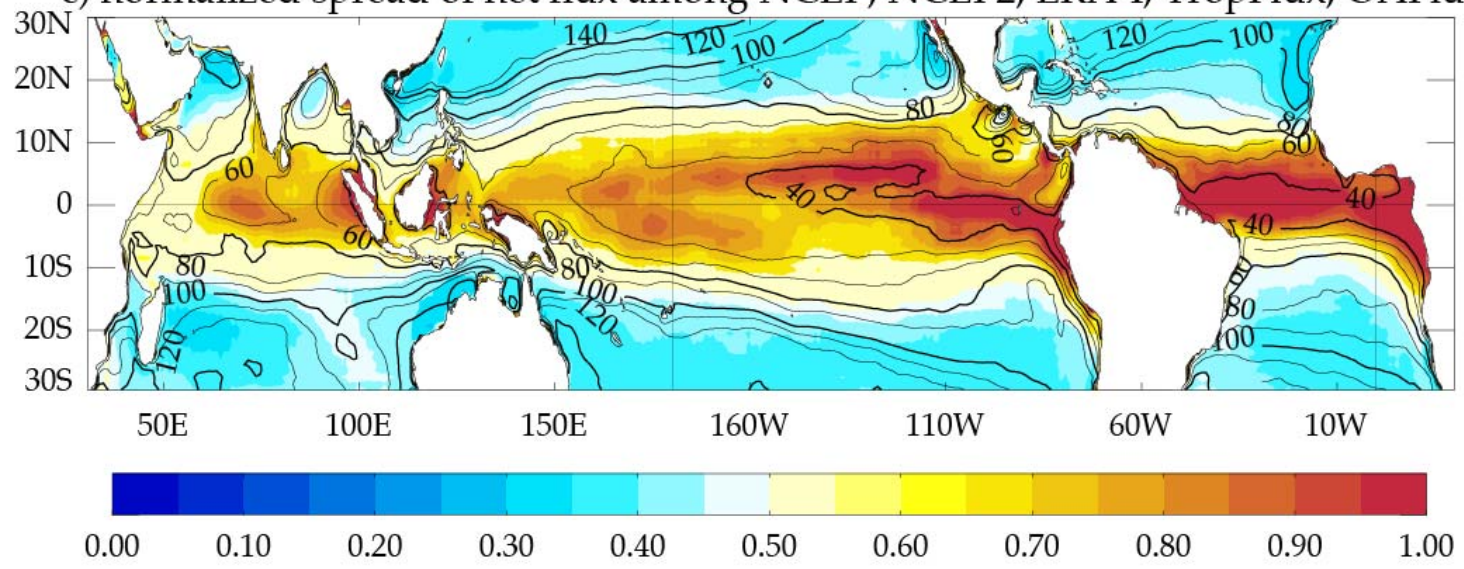

Figure 16: Ensemble spread (see text for details) of (a) wind stress magnitude from NCEP, NCEP2, ERA-I, TropFlux and QuikSCAT, (b) wind stress magnitude from NCEP, NCEP2, ERA-I and TropFlux and (c) net heat flux from NCEP, NCEP2, ERA-I, OAFlux and TropFlux. The contours show the standard deviation of the average of the products. 